\section{GROUNDED THEORY COM UTILIZAÇÃO DO SOFTWARE ATLAS.TI: UM EXEMPLO EMPÍRICO DE ESTUDO SOBRE ESTRATÉGIA DE ASCENSÃO DO EMPREENDEDORISMO INOVADOR EM NEGÓCIOS SOCIAIS}

Objetivo do estudo: Explorar como se dá a estratégia de ascensão do empreendedorismo inovador, em negócios sociais, que qualificam a oferta de produtos e serviços educacionais e da saúde.

Metodologia/abordagem: Foi adotada a pesquisa qualitativa denominada Grounded Theory, fundamentada em dados empíricos. Para tal, foi construído um exemplo didático, com a utilização detalhada do Software ATLAS.ti. A unidade hermenêutica (projeto no ATLAS.ti) contemplou os seguintes documentos primários: (a) histórias de vida de seis empreendedores sociais, (b) relatórios sobre o desenvolvimento dos negócios sociais (Cren, Cies, Geekie, Imaflora, Educar e Noos) e (c) depoimentos dos indivíduos impactados.

Principais resultados: Em relação aos principais resultados, destaca-se o detalhamento didático sobre como o ATLAS.ti foi utilizado como apoio às codificações (aberta, axial e seletiva), que fundamentam a Grounded Theory, promovendo a organização, recuperação e cruzamento de dados acerca da estratégia de ascensão do empreendedorismo inovador em negócios sociais;

Contribuições teóricas/metodológicas: A principal contribuição foi a proposição de uma matriz de alinhamento da Grounded Theory, com utilização detalhada do Software ATLAS.ti, considerando como exemplo didático a estratégia de ascensão do empreendedorismo inovador, em negócios sociais, que qualificam a oferta de produtos e serviços educacionais e da saúde.

Relevância/originalidade: Foi possível demonstrar as associações entre categorias e subcategorias de análise do estudo a partir de componentes característicos do ATLAS.ti (não disponíveis em outros CAQDAS), como Code Cooccurence e Networks.

Palavras-chave: Grounded Theory. ATLAS.ti. Empreendedorismo Inovador. Negócios Sociais.
Priscila Rezende da Costa

Doutora em Administração pela Faculdade de Economia, Administração e Contabilidade da Universidade de São Paulo - FEA/USP. Coordenadora do Programa de Pós-Graduação em Administração da Universidade Nove de Julho - PPGA/UNINOVE. Brasil. E-mail: priscilarc@uni9.pro.br

Lucimar da Silva Itelvino

Doutora em Educação pela Universidade Nove de Julho - UNINOVE. Coordenadora e professora do curso de Administração da Universidade Nove de Julho - UNINOVE. Brasil. E-mail: lucimarsilva@uninove.br

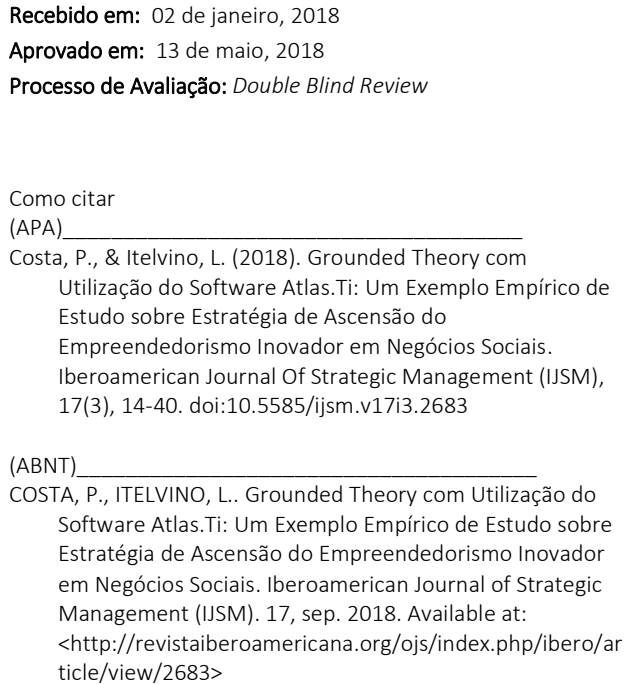




\section{GROUNDED THEORY WITH THE USE OF THE ATLAS.TI SOFTWARE: AN EMPIRICAL EXAMPLE OF A STUDY ON THE ASCENTING STRATEGY OF INNOVATIVE ENTREPRENEURSHIP IN SOCIAL BUSINESS}

Purpose of the study: To explore how the innovative entrepreneurship strategy of social entrepreneurship qualifies the offer of educational and health products and services.

Methodology / approach: We adopt the qualitative research termed Grounded Theory, based on empirical data. For this purpose, we develop a didactic example, with the detailed use of the ATLAS.ti Software. The hermeneutical unit (project in ATLAS.ti) contemplated the following primary documents: (a) life stories of six social entrepreneurs; (b) reports on the development of social affairs (Cren, Cies, Geekie, Imaflora, Educar and Noos) and (c) testimonials of impacted individuals.

Main results: In relation to the main results, we highlight the didactic detail on how ATLAS.ti is used to support the codings (open, axial and selective), which underpin the Grounded Theory, promoting the organization, recovery and cross-referencing of data about the strategy of the rise of innovative entrepreneurship in social affairs;

Theoretical / methodological contributions: The main contribution is the proposition of a Grounded Theory alignment matrix, with detailed use of the ATLAS.ti Software, considering as a didactic example the strategy of the rise of innovative entrepreneurship in social businesses, which qualify the supply of education and health products and services.

Relevance / originality: We are able to demonstrate the associations between categories and subcategories of study analysis from characteristic components of ATLAS.ti (not available in other CAQDAS), such as Code Cooccurence and Networks.

Keywords: Grounded Theory. ATLAS.ti. Innovative Entrepreneurship. Social Business.

\section{GROUNDED THEORY CON LA UTILIZACIÓN DEL SOFTWARE ATLAS.TI: UN EJEMPLO EMPÍRICO DE ESTUDIO SOBRE ESTRATEGIA DE ASCENSIÓN DEL EMPRENDIMIENTO INNOVADOR EN NEGOCIOS SOCIALES}

Objetivo del estudio: Explorar cómo se da la estrategia de ascenso del emprendimiento innovador, en negocios sociales, que califica la oferta de productos y servicios educativos y de salud.

Metodología / enfoque: Se adoptó la investigación cualitativa denominada Grounded Theory, fundamentada en datos empíricos. Para ello, se construyó un ejemplo didáctico, con la utilización detallada del Software ATLAS.ti. La unidad hermenéutica (proyecto en el ATLAS.ti) contempló los siguientes documentos principales: (a) historias de vida de seis emprendedores sociales, (b) informes sobre el desarrollo de los negocios sociales (Cren, Cies, Geekie, Imaflora, Educar y Noos) y (c) testimonios de los individuos afectados.

Principales resultados: En relación a los principales resultados, se destaca el detalle didáctico sobre cómo el ATLAS.ti fue utilizado como apoyo a las codificaciones (abierta, axial y selectiva), que fundamentan a Grounded Theory, promoviendo la organización, recuperación y cruce de datos sobre la estrategia de ascenso del emprendimiento innovador en negocios sociales;

Contribuciones teóricas / metodológicas: La principal contribución fue la proposición de una matriz de alineación de Grounded Theory, con utilización detallada del Software ATLAS.ti, considerando como ejemplo didáctico la estrategia de ascensión del emprendimiento innovador, en negocios sociales, que califican la oferta de productos y servicios educativos y salud.

Relevancia / originalidad: Es posible demostrar las asociaciones entre categorías y subcategorías de análisis del estudio a partir de componentes característicos del ATLAS.ti (no disponibles en otros CAQDAS), como Code Cooccurence y Networks.

Palabras clave: Grounded Theory. ATLAS.ti. Emprendimiento Innovador. Negocios Sociales. 
Grounded Theory com Utilização do Software Atlas.Ti: Um Exemplo Empírico de Estudo sobre Estratégia de Ascensão do Empreendedorismo Inovador em Negócios Sociais

\section{INTRODUÇÃO}

O objetivo foi explorar como se dá a estratégia de ascensão do empreendedorismo inovador, em negócios sociais, que qualificam a oferta de produtos e serviços educacionais e da saúde. Sobre a abordagem metodológica, foi adotada a pesquisa qualitativa denominada Grounded Theory, fundamentada em dados empíricos, com a utilização detalhada do Software ATLAS.ti., versão 7.5, desenvolvido pela Scientific Software Development. Para tanto, foi construído um exemplo didático, recuperando os resultados de pesquisas já publicadas, que contemplaram a estratégia de ascensão do empreendedorismo inovador em negócios sociais, qualificadores da oferta de produtos e serviços educacionais e da saúde.

Dessa forma, o leitor pode ter acesso aos resultados e discussões das pesquisas, de forma mais detalhada, acessando os artigos na íntegra, sendo eles: (1) Formação Empreendedora para Geração de Inovações Sociais: Um Levantamento com Empreendedores Sociais Brasileiros (Prêmio de melhor artigo da Divisão de Gestão da Ciência, Tecnologia e Inovação do XXXIX Encontro da Associação Nacional de Pós-Graduação e Pesquisa em Administração EnANPAD) (Itelvino, Costa, Gohn \& Ramacciotti, 2015); (2) Atuação Sustentável para o Desenvolvimento de Inovações Sociais: Um Estudo com Negócios de Impacto Social (Costa \& Itelvino, 2016); (3) Formação Empreendedora para Geração de Inovações Sociais (Itelvino, Costa, Gohn, Ramacciotti, \& Porto, 2018); (5) Formação do empreendedor social e a educação formal e não formal: um estudo a partir de narrativas de história de vida (Itelvino, Costa, Gohn \& Ramacciotti, 2018).

Cabe considerar que, nos artigos indicados, o número de sujeitos e negócios sociais é maior, tendo sido utilizada apenas uma parte da base de dados da pesquisa, de forma a demonstrar didaticamente as etapas da Grounded Theory e os procedimentos de utilização do Software ATLAS.ti.

Nos próximos itens, são detalhados os comandos de utilização do software ATLAS.ti, bem como as etapas que direcionaram a Grounded Theory, a saber: problematização; delineamento metodológico; codificações (aberta, axial e seletiva); e, por fim, conclusões e referências.

\section{CONTEXTUALIZAÇÃO E ABORDAGEM METODOLÓGICA}

A Grounded Theory é uma metodologia de criação de teorias substantivas, a partir de uma análise indutiva de dados empíricos, sendo, portanto, adequada ao estudo de problemas de pesquisa ainda não consolidados na literatura e que demandam tratamento contextual (Strauss \& Corbin, 2008; Frezatti, Nascimento, Junqueira \& Sordi, 2011; Corbin, 2017).

Como exemplo, destaca-se a estratégia de ascensão do empreendedorismo inovador, em negócios sociais, que qualificam a oferta de produtos e serviços educacionais e da saúde para a base da pirâmide (Itelvino, Costa, Gohn \& Ramacciotti, 2015; Costa \& Itelvino, 2016; Itelvino, Costa, Gohn, Ramacciotti \& Porto, 2018), cujo contexto e problematização são apresentados a seguir.

No Brasil, aproximadamente de $72 \%$ da população depende exclusivamente do Sistema Único de Saúde (SUS), segundo dados do IBGE (Instituto Brasileiro de Geografia e Estatística, 2013), de 2013 (estatística mais recente). Apesar da oferta gratuita e universal, o serviço prestado pelo SUS enfrenta severas restrições de qualidade, acesso e eficiência, tais como: insuficiência de leitos; superlotação de emergências hospitalares; carência de profissionais de saúde; desigualdade na distribuição de médicos no País; falta de medicamentos e insumos hospitalares; e estrutura física inadequada (Tribunal De Contas De União [TCU], 2014; Sousa, Medeiros, Gurgel \& Albuquerque, 2014; Aguiar \& Vasconcellos, 2015).

Outros entraves ao mercado de Saúde também podem ser enfatizados, tais como: a regulação, inexistente ou desatualizada, que bloqueia o desenvolvimento de algumas atividades, como microsseguros e telemedicina; atuação deficiente do SUS para estabelecer medidas preventivas de saúde e controle de epidemias (em especial, dengue), bem como a lentidão nos encaminhamentos às especialidades médicas $\mathrm{e}$ cirúrgicas; a morosidade na aquisição de novos produtos e serviços em saúde, especialmente os que agregam tecnologias inéditas; serviços oferecidos pela iniciativa privada em uma faixa de preço acessível à classe $\mathrm{C}$, mas inviáveis às classes $\mathrm{D}$ e $\mathrm{E}$ (Prospectiva, 2015a; Sousa, Medeiros, Gurgel \& Albuquerque, 2014; Aguiar \& Vasconcellos, 2015). Quanto às deficiências dos serviços educacionais públicos, tem-se o seguinte panorama: baixa qualidade dos programas de formação de professores; desvalorização da carreira docente; método pedagógico desconectado da realidade do aluno; ineficiência na gestão educacional e administrativa; infraestrutura escolar precária; baixo acesso à educação infantil e técnica; e restrições de financiamento (mau uso dos recursos) (Freire, 2014; Prospectiva, 2015b; Linhares, 2017). 
Grounded Theory com Utilização do Software Atlas.Ti: Um Exemplo Empírico de Estudo sobre Estratégia de Ascensão do Empreendedorismo Inovador em Negócios Sociais

Portanto, é notória a problemática pública brasileira, com demandas negligenciadas e políticas pouco efetivas para a educação e a saúde. Por outro lado, esse contexto demonstra a oportunidade de desenvolvimento, no Brasil, de negócios que atendam à população de baixa renda (Prahalad, 2005; Kolk, Rivera-Santos \& Rufin, 2014), evidenciando, portanto, a relevância de estudos exploratórios sobre empreendedores e seus negócios sociais (Sinkovics, Sinkovics \& Yamin, 2014), que atuam oportunamente e de forma inovadora na qualificação da oferta de produtos e serviços para a base da pirâmide (Farfus \& Rocha, 2007; Juliani, Juliani, Souza \& Harger, 2014; Angot \& Plé, 2015; Silvestre, 2014), particularmente na saúde e na educação.

Sendo assim, a oportunidade de desenvolver negócios baseados na inovação social, enquanto processo aberto e colaborativo, que resulta na transformação social (Sousa, Mendonça, Sousa \& Santos, 2014; Mulgan, Tucker \& Sanders, 2007), abre espaço para reforçar a necessidade de legitimação dos empreendedores e seus negócios sociais, bem como denota a relevância de se buscar um ambiente de inovação social mais profissionalizado e sustentável (Cajaiba-Santana, 2014; Phillips, Lee, Ghobadian, O’Regan \& James, 2015).

Dessa forma, nesse exemplo didático de pesquisa, construído a partir de fontes secundárias de evidência (Itelvino, Costa, Gohn \& Ramacciotti, 2015; Costa \& Itelvino, 2016; Itelvino, Costa, Gohn, Ramacciotti \& Porto, 2018), o objetivo foi explorar como se dá a estratégia de ascensão do empreendedorismo inovador, em negócios sociais, que qualificam a oferta de produtos e serviços educacionais e da saúde.

Adotou-se a abordagem indutiva, fundamentada nos dados empíricos (Grounded Theory), a partir do paradigma qualitativo que, segundo Charmaz (2009), oferece uma compreensão detalhada dos significados e das características situacionais apresentadas pelos objetos da investigação.

Dessa forma, nota-se que o paradigma qualitativo e a Grounded Theory são aderentes e ambos contemplam uma perspectiva naturalista, dado que a realidade subjetiva analisada é resultado das interações entre os atores participantes (Furlanetti \& Barros, 2013; Frezatti, Nascimento, Junqueira \& Sordi, 2011; Ahrens \& Chapman, 2007; Berry \& Otley, 2004).

Ainda sobre a Grounded Theory, Straus e Corbin (2008), Charmaz (2009) e Corbin (2017) enfatizam que a abordagem requer pensamento criativo no processo de teorização, sendo assim, o pesquisador deve colocar em prática a capacidade de retroceder e analisar situações de forma crítica e reflexiva e ter sensibilidade em relação às palavras e às ações dos sujeitos investigados. Destaca-se, ainda, que o processo da Grounded Theory envolve conceituar (codificação aberta) e reduzir dados (codificação axial e seletiva), elaborando categorias em termos de suas propriedades (Straus \& Corbin, 2008; Corbin, 2017).

Para Strauss e Corbin (2008), na codificação aberta, também denominada de substantiva, deve-se examinar minuciosamente os dados brutos (microanálise), a partir das palavras-chave, frases ou parágrafos, visando à identificação de conceitos, ou seja, propriedades que definem e dão significado ao fenômeno investigado. Além disso, as propriedades são também agrupadas em categorias conceituais, como forma de dimensionar e reduzir a extensão dos dados coletados.

A segunda codificação realizada é a axial, na qual as categorias identificadas na codificação aberta são, então, reagrupadas - sendo axial porque ocorre ao redor de um fluxo de comparações contínuas e sucessivas para buscar a redução dos dados. As categorias são então comparadas, relacionadas e interconectadas, envolvendo, portanto, a classificação das mesmas em: contexto, condições intervenientes, condições causais, estratégias e consequências do fenômeno (Furlanetti \& Barros, 2013; Dantas, Leite, Lima, \& Stipp 2009; Corbin, 2017).

Na codificação seletiva, por sua vez, tem-se a identificação da categoria central do fenômeno investigado, bem como das suas subcategorias. Para ela, adota-se um grau mais elevado de abstração, cujos resultados podem assumir a forma de teoria substantiva, modelo conceitual explicativo ou matriz teórica (Furlanetti \& Barros, 2013; Dantas et al. 2009; Corbin, 2017).

Segundo Strauss e Corbin (1998), o ciclo de codificação (fases aberta, axial e seletiva) deve ser finalizado quando é alcançada a saturação teórica, ou seja, próximo ao momento em que os ganhos de explicação do fenômeno, ao se realizar amostragens teóricas, serão nulos: no retorno aos dados brutos não são identificadas novas propriedades ou categorias com poder de explicação relevante.

Em relação aos critérios de validade interna, confiabilidade e validade externa: (1) sobre a "validade interna", na Grounded Theory, deve-se considerar que a realidade é construída socialmente, a partir da percepção dos indivíduos; sendo assim, o pesquisador descobre a realidade observada por meio dos dados coletados; (2) em relação à "confiabilidade", há de se considerar que o comportamento humano não é conduzido por leis e normas universais, que promovem resultados iguais; então, a confiabilidade é a consistência entre os resultados da pesquisa e os dados empíricos coletados 
Grounded Theory com Utilização do Software Atlas.Ti: Um Exemplo Empírico de Estudo sobre Estratégia de Ascensão do Empreendedorismo Inovador em Negócios Sociais

no campo; (3) quanto à "validade externa", o foco, na Grounded Theory, é descobrir as condições em que ocorrem determinados incidentes, bem como suas causas e consequências; portanto, quanto maior as variações nas diferentes condições descobertas, mais geral é a teoria substantiva criada (Strauss \& Corbin, 1998; Hom \& Takacs, 2007; Bergh et al., 2016).

Em relação à operacionalização da pesquisa, adotou-se a abordagem de Strauss e Corbin (2008), dado que o objetivo da pesquisa foi formulado antecipadamente à operacionalização do estudo, além disso, realizou-se o reducionismo dos dados, a partir de comandos do software ATLAS.ti que, segundo Lee e Esterhuizen (2000) e Woods, Paulus, Atkins e Macklin (2016), possibilita a organização e a recuperação de informações relacionadas à ideia ou ao conceito subjacente ao fenômeno investigado, o que é importante para estruturar e validar empiricamente citações, memorandos e códigos, no processo de retorno aos dados qualitativos.

\section{DEFININDO A UNIDADE HERMENÊUTICA}

A unidade hermenêutica envolveu o projeto criado no ATLAS.ti, aqui intitulado, como exemplo didático de codificação, em "empreendedorismo social para inovação social". Criada a unidade hermenêutica, foram adicionados, no ATLAS.ti, os "documentos primários", ou seja, os "dados brutos", coletados no formato de texto (Figura 1).

Sobre as unidades de análise, examinou-se seis empreendedores e seus respectivos negócios sociais, vencedores do Prêmio Empreendedor Social, do Jornal Folha de São Paulo: Educar, Geekie, Imaflora e Noos (com atuação na área da educação); Cren e Cies (com atuação na área da saúde). A partir dessas unidades de análise, os documentos primários utilizados foram: (a) histórias de vida de empreendedores sociais, (b) relatórios sobre o desenvolvimento dos negócios sociais e (c) depoimentos dos indivíduos impactados, totalizando 18 documentos primários (de $\mathrm{P} 1$ até $\mathrm{P} 18$ ), visto que a pesquisa contemplou 6 empreendedores e seus respectivos negócios sociais.

Nas figuras a seguir são representados os comandos realizados no ATLAS.ti para a criação da unidade hermenêutica (Figura 1) e a inserção dos documentos primários (Figura 2).

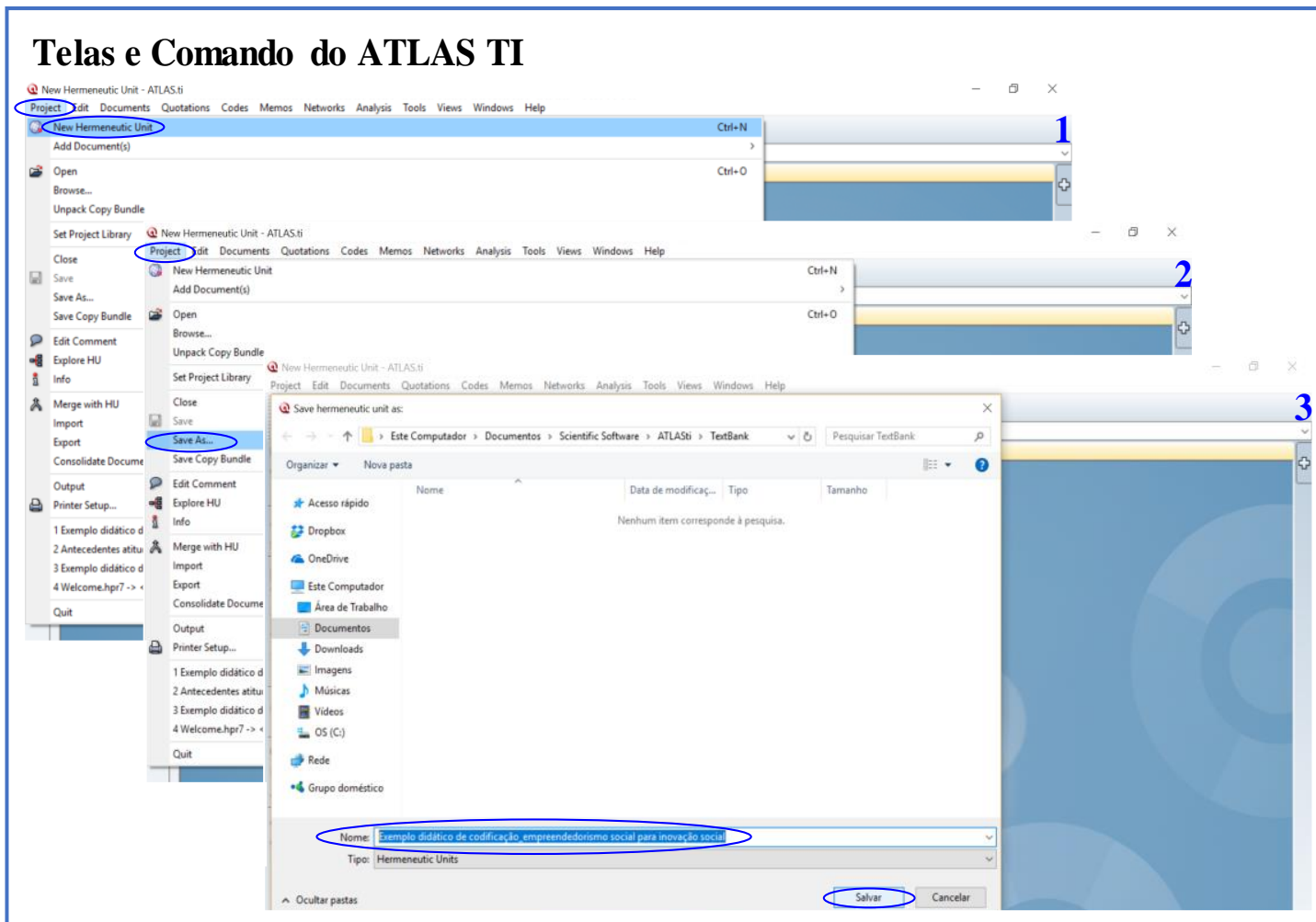

Tela $1<$ Project $>\langle$ New Hermeneutic Unit $>$; Tela $2<$ Project $>\langle$ Save As $>$; Tela 3 inserir nome projeto $>\langle$ Salvar $\rangle$.

Figura 1 - Criação da unidade hermenêutica no ATLAS.ti

Fonte: Elaborada pelas autoras 
Grounded Theory com Utilização do Software Atlas.Ti: Um Exemplo Empírico de Estudo sobre Estratégia de Ascensão do Empreendedorismo Inovador em Negócios Sociais

\section{Telas e Comandos do ATLAS TI}

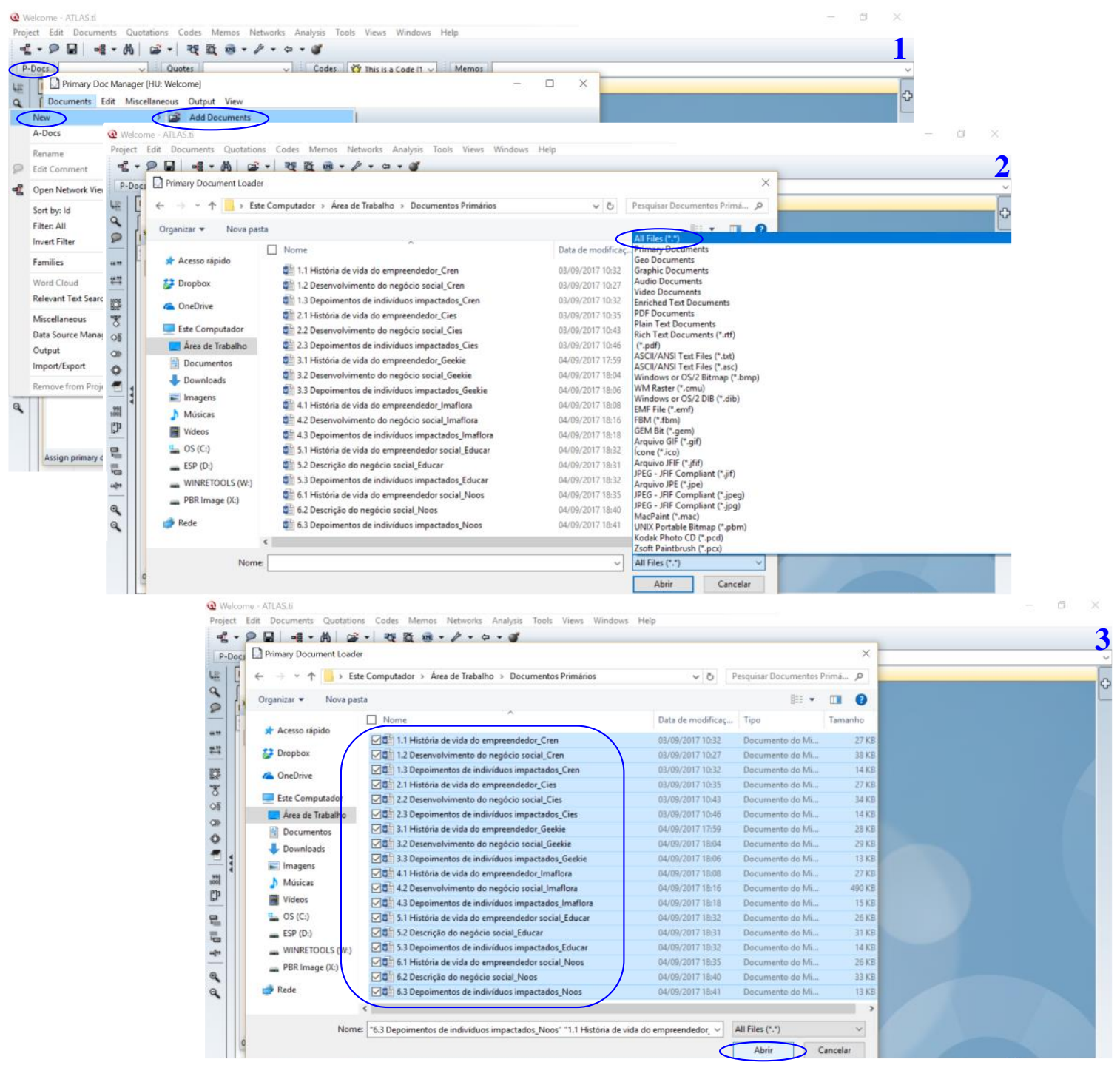

$\underline{\text { Tela } 1}<$ P-Docs $><$ Documents $><$ New $><$ Add Dcouments $>$; Tela $2<$ All Files $(* . *)>$; Tela $3<$ Abri $>$.

Figura 2 - Inserção dos documentos primários no ATLAS.ti Fonte: Elaborada pelas autoras

\section{CODIFICANDO OS DOCUMENTOS PRIMÁRIOS}

A codificação dos documentos primários, no ATLAS.ti, envolve ações como conceituar e reduzir dados; elaborar categorias, a partir de suas propriedades, relacionando-as ao fenômeno investigado. Para isso, recorreu-se à codificação aberta, axial e seletiva (Straus \& Corbin, 2008; Corbin, 2017).
Durante as fases de codificação, três análises foram fundamentais: (1) busca de significado (descoberta de uma nova propriedade que definiu e deu significado ao fenômeno investigado); (2) realização de comparação teórica (quando a nova propriedade contribui para a identificação de uma nova categoria conceitual do fenômeno investigado); (3) realização de comparação incidente-incidente (quando a nova propriedade descoberta é associada a uma categoria conceitual já existente, aumentando sua 
Grounded Theory com Utilização do Software Atlas.Ti: Um Exemplo Empírico de Estudo sobre Estratégia de Ascensão do Empreendedorismo Inovador em Negócios Sociais

fundamentação). Essas análises também foram fundamentais para indicar a saturação teórica após os ciclos de codificação (aberta, axial e seletiva), ou seja, evidenciar que, no retorno aos dados brutos, não foram identificadas novas propriedades ou categorias com poder de explicação relevante (Corbin, 2017).

Especificamente, no projeto didático de codificação considerado, foram adotados os seguintes procedimentos de codificação (Figura 3), com da utilização do ATLAS.ti.

$\mathrm{Na}$ codificação aberta, descobriu-se as propriedades que definiram e deram significado ao fenômeno investigado, sendo representadas, no ATLAS.ti, por citações $(Q U A T A T I O N S=$ fragmentos relevantes do texto) e memorandos $(M E M O S=$ notas sobre a interpretação do pesquisador). A partir de comparações contínuas e sucessivas, determinadas propriedades contribuíram para a identificação de novas categorias conceituais (comparações teóricas); outras foram associadas às categorias conceituais já existentes (comparações incidente-incidente). No ATLAS.ti, as categorias conceituais tiveram a representação em códigos $(C O D E S=$ conjunto de citações e memorandos que fundamentam o fenômeno investigado).

Na codificação axial, foi adotado, também, um fluxo de comparações contínuas e sucessivas, para reagrupar as categorias por coocorrência, como forma de dimensionar e reduzir a extensão dos dados coletados. Além disso, as categorias foram relacionadas por densidade (quantidade de vínculos), em uma visão de rede (proposição), de forma a representar o contexto, as condições intervenientes, as condições causais, estratégias e consequências do fenômeno investigado. As categorias reagrupadas foram representadas, no ATLAS.ti, por família de códigos (FAMILIE CODE = agrupamento de códigos) e seus relacionamentos, por densidade (quantidade e direção dos vínculos entre os códigos).

$\mathrm{Na}$ codificação seletiva, por sua vez, foi identificada a categoria central do fenômeno, ou seja, aquela que assumiu ponto de centralidade, na visão de rede, sendo o receptor do maior número de vínculos (maior densidade): "is associated with"; "is property of"; "is context for"; "is intervening condition for"; "Is strategy for"; "is causal condition for"; e "is consequence of". Além disso, foram identificadas as subcategorias da categorial central, ou seja, as que representam o nó de origem dos vínculos citados. Destacam-se, também, a validação da categoria central do estudo a partir de um grupo focal, com empreendedores sociais; e a representação, no ATLAS.ti, dessa categoria, por uma "SUPER FAMILIE CODE” (família de código superior).

\begin{tabular}{|c|c|c|}
\hline $\begin{array}{l}\text { Procedimentos de } \\
\text { codificação }\end{array}$ & Na Grounded Theory & No ATLAS.ti \\
\hline $\begin{array}{l}\text { Codificação } \\
\text { Aberta }\end{array}$ & $\begin{array}{l}\text { Identificar propriedades e agrupá- } \\
\text { las em categorias conceituais. }\end{array}$ & $\begin{array}{l}\text { Identificar citações (QUATATIONS = fragmentos } \\
\text { relevantes do texto) e memorandos (MEMOS = notas } \\
\text { sobre a interpretação do pesquisador) e agrupá-los em } \\
\text { códigos ( } C O D E S=\text { conjunto de citações e memorandos } \\
\text { que fundamentam o fenômeno investigado). }\end{array}$ \\
\hline Codificação Axial & $\begin{array}{l}\text { Agrupar categorias e relacioná- } \\
\text { las. }\end{array}$ & $\begin{array}{l}\text { Agrupar códigos em famílias de códigos (FAMILIES } \\
C O D E S=\text { agrupamento de códigos por coocorrência) e } \\
\text { relacioná-los em uma visão de rede (NETWORK VIEW } \\
=\text { quantidade e direção dos vínculos dos códigos). }\end{array}$ \\
\hline $\begin{array}{l}\text { Codificação } \\
\text { Seletiva }\end{array}$ & $\begin{array}{l}\text { Identificar categoria central do } \\
\text { fenômeno e suas subcategorias. }\end{array}$ & $\begin{array}{l}\text { Identificar família de código superior (SUPER } \\
\text { FAMILIE CODE = família com o maior número de } \\
\text { vínculos) e suas subcategorias (FAMILIES CODES = } \\
\text { famílias de códigos com número inferior de vínculos). }\end{array}$ \\
\hline
\end{tabular}

Figura 3 - Procedimentos de codificação na Grounded Theory e no ATLAS.ti Fonte: Elaborada pelas autoras.

\section{Detalhamento da codificação aberta}

Em termos de exemplificação didática (Figura 4), tem-se a codificação aberta da história de vida (documento primário $\mathrm{P} 1$ ) da empreendedora "Gisela" do negócio social "Cren", com a codificação da propriedade "contato com a desigualdade", na forma de citação (no ATLAS.ti, representada por “QUATATIONS"), e também da propriedade "referência familiar", na forma de memorando (no ATLAS.ti, representada por “MEMOS").

Destaca-se que, no ATLAS.ti, as citações são referenciadas pelo número do documento primário onde estão localizadas, seguido do seu número de 
Grounded Theory com Utilização do Software Atlas.Ti: Um Exemplo Empírico de Estudo sobre Estratégia de

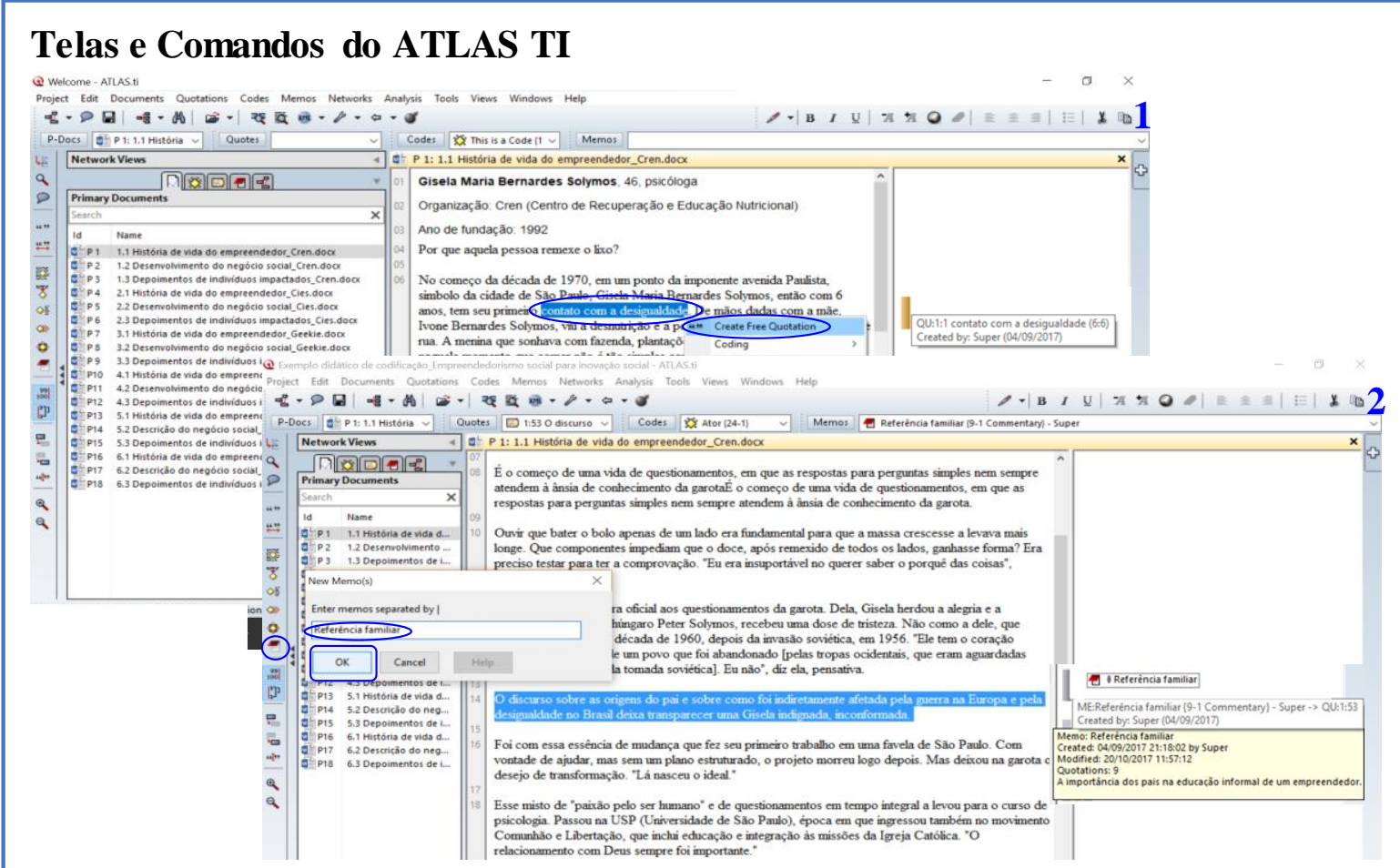

Tela $1<$ Clique com o botão direto do mouse sobre a citação selecionada $><$ Create Free Quottation $>$;

$\underline{\text { Tela } 2}<$ New Memo><inserir memorando $>\langle$ ok $>$.

Figura 4 - Identificação de propriedades (codificação aberta), representadas no ATLAS.ti por “QUATATIONS” e "MEMOS"

Fonte: Elaborada pelas autoras.

A seguir, são apresentadas algumas propriedades relevantes, que foram identificadas nos documentos primários analisados (Figura 5), representadas pelas citações recuperadas e selecionadas, a partir do menu "codercode manager $>$ " do ATLAS.ti.

\begin{tabular}{|c|l|}
\hline $\begin{array}{c}\text { Relatórios sobre o } \\
\text { desenvolvimento dos } \\
\text { negócios sociais (6 } \\
\text { documentos } \\
\text { primários) }\end{array}$ & \multicolumn{1}{|c|}{$\begin{array}{c}\text { Algumas propriedades identificadas na codificação aberta que } \\
\text { definiram e deram significado ao fenômeno investigado }\end{array}$} \\
\hline $\begin{array}{c}\text { 1.2 Desenvolvimento } \\
\text { do negócio social }\end{array}$ & $\begin{array}{l}\text { (1) Os recursos são obtidos a partir de parcerias com o poder público municipal, de doações, de } \\
\text { projetos incentivados e da venda de produtos em bazares; (2) A origem foi de um projeto de } \\
\text { extensão da Unifesp e depois de comprovada a eficiência de sua metodologia, tornou-se referência } \\
\text { na prevenção e tratamento de distúrbios nutricionais; hoje conta com duas unidades prestadoras de } \\
\text { serviço em São Paulo, equipe de campo em Jundiaí e uma unidade em Maceió (AL); } \\
\text { academicamente, a organização trabalhou em cooperação com instituições nacionais e e } \\
\text { internacionais; (3) Benefício direto a mais de 50 mil pessoas, desde seu início, segundo dados } \\
\text { quantitativos e qualitativos devidamente registrados e com embasamento científico de mensuração } \\
\text { de impacto, decorrente de projeto acadêmico da Unifesp; os impactos gerados pela intervenção } \\
\text { superam os ganhos na saúde dos atendidos e geram também mudanças estruturais e sociais nas } \\
\text { famílias atendidas; (4) Compilação de conhecimentos, iniciativas e resultados com rigor científico }\end{array}$ \\
\hline
\end{tabular}


Grounded Theory com Utilização do Software Atlas.Ti: Um Exemplo Empírico de Estudo sobre Estratégia de Ascensão do Empreendedorismo Inovador em Negócios Sociais

\begin{tabular}{|c|c|}
\hline & $\begin{array}{l}\text { em planos de trabalho político-pedagógico e em artigos científicos; como exemplo, destaca-se o } \\
\text { lançamento da coleção e do portal Vencendo a Desnutrição, com recursos do BNDES. Cabe também } \\
\text { citar a parceria com a Fundação Avsi, da Itália, para o desenvolvimento de um projeto de e-learning } \\
\text { com } 32 \text { Centros de Educação Infantil em cinco cidades brasileiras; e pontuar, ainda, a replicação } \\
\text { autônoma das metodologias inovadoras do instituto em outros países, como Haiti, Honduras, Itália, } \\
\text { México, Moçambique e Peru; (5) Realização de curso de especialização para os gestores de saúde, a } \\
\text { fim de tutorar a aplicação da metodologia do censo antropométrico nas campanhas de vacinação; } \\
\text { destaca-se, igualmente, a atuação do instituto em complementar o Programa Saúde da Família; e, em } \\
\text { São Paulo, vale mencionar a implantação da educação nutricional em centros de educação infantil, } \\
\text { usando a metodologia de oficinas práticas. }\end{array}$ \\
\hline $\begin{array}{l}\text { 2.2 Desenvolvimento } \\
\text { do negócio social } \\
\text { Cies.docx }\end{array}$ & $\begin{array}{l}\text { (1) O projeto foi baseado em um modelo de autossustentabilidade financeira, em que as principais } \\
\text { fontes de receita vêm na forma de prestação de serviços ao poder público, com base na tabela SUS e } \\
\text { em doações de empresas com renúncia fiscal; os custos do evento são minimizados por parcerias } \\
\text { com empresas locais, governo, associações civis e comunidade; (2) A concepção final e a construção } \\
\text { do centro médico avançado ocorreram na cidade de São Paulo, sendo que, desde então, foram } \\
\text { realizados atendimentos em } 12 \text { cidades; houve a procura espontânea de mais de } 50 \text { cidades, para } \\
\text { construção de novas unidades; fora do país, há negociaçães com Angola, Colômbia, Itália, Nigéria, } \\
\text { Panamá e Venezuela; (3) O projeto registrou mais de } 24 \text { mil pessoas atendidas, tendo realizado mais } \\
\text { de } 40 \text { mil exames e procedimentos cirúrgicos, além de ter dado treinamento a mais de } 500 \text { agentes; } \\
\text { (4) O Projeto foi concebido com vistas à replicação em grande escala, sobretudo nas regiões mais } \\
\text { pobres e com precário atendimento médico, sendo contínuo o esforço de pesquisa e desenvolvimento } \\
\text { com contêineres e vans para gerar maior flexibilidade, impacto e eficiência; os procedimentos } \\
\text { técnicos de replicação do projeto estão sistematizados em documentos, como manuais de montagem } \\
\text { e operação, que detalham os processos que devem ser efetuados dentro dos padrões exigidos por } \\
\text { órgãos fiscalizadores e de acreditação; (5) Forte ligação com políticas públicas de saúde, a partir de } \\
\text { parceria com o governo local; complemento do atendimento das unidades básicas de saúde, dos } \\
\text { ambulatórios de especialidades, dos programas de saúde da família e de internação domiciliar. Outra } \\
\text { premissa é contribuir para a diminuição das filas de espera nos hospitais; e elaboração de uma } \\
\text { análise crítica do sistema de saúde pública local, por meio da identificação de focos de ociosidade e } \\
\text { de investimento inoperante. }\end{array}$ \\
\hline $\begin{array}{l}\text { 3.2 Desenvolvimento } \\
\text { do negócio social } \\
\text { Geekie.docx }\end{array}$ & $\begin{array}{l}\text { (1) Investimento público e privado; contratação de profissionais experientes, profissionalização da } \\
\text { equipe, adoção de sistema de gestão e área formal de gestão de pessoas; (2) O Geekie Games foi } \\
\text { utilizado por alunos de todos os Estados, sendo que } 80 \% \text { dos } 2 \text { milhões de alunos cadastrados vieram } \\
\text { de escolas públicas; (3) A plataforma de preparação para o Enem é utilizada por, aproximadamente, } \\
40 \% \text { dos estudantes que realizaram a prova; contratos estabelecidos com cerca de } 500 \text { escolas, sob a } \\
\text { premissa "onepay, onefree" (cada aluno pago gera oportunidade para outro estudante de escola } \\
\text { pública); estabelecidas parcerias com secretarias de ensino para o alcance integrado de mais de } 100 \\
\text { mil alunos, fornecendo também às escolas recursos de avaliação diagnóstica e gestão da } \\
\text { aprendizagem; (4) Plataforma de preparação gratuita para o Enem é altamente replicável, } \\
\text { promovendo a democratização do ensino em nível federal; destaca-se, também, a personalização da } \\
\text { aprendizagem ao contexto educativo das escolas parcerias; (5) A organização foi certificada pelo } \\
\text { Inep como tecnologia confiável de simulação do Enem; em 2014, o Geekie Games atingiu } 19 \text { dos } 26 \\
\text { Estados, impactando mais de } 17 \text { mil escolas. }\end{array}$ \\
\hline $\begin{array}{l}\text { 4.2 Desenvolvimento } \\
\text { do negócio social } \\
\text { Imaflora.docx }\end{array}$ & $\begin{array}{l}\text { (1) Parcerias com empresas, órgãos públicos, instituições de ensino e organizações do terceiro setor; } \\
\text { diversificação e gestão eficaz permitem satisfatório e adequado nível de solidez/fidelidade nas } \\
\text { parcerias; atuações do Conselho Diretor e da Assembleia Geral de Associados, com } \\
\text { responsabilidades deliberativas; há um Conselho Consultivo e um Conselho Fiscal que fornecem } \\
\text { subsídios para o Conselho Diretor, a Assembleia Geral e a Secretaria Executiva tomarem decisões } \\
\text { estratégicas; (2) Conduz certificações em nível nacional, atingindo } 25 \text { Estados; desenvolveu projetos } \\
\text { comunitários e de manejo no Amapá, no Pará, na Bahia, em São Paulo e também de cooperação } \\
\text { internacional com Gana e Camarões; (3) É referência, no país, em certificação socioambiental; sua } \\
\text { área de atuação é de cerca de } 15,2 \text { milhões de hectares; conduziu certificações em cerca de } 140 \\
\text { empreendimentos, beneficiou 120.000 trabalhadores florestais e agrícolas e } 410 \text { famílias nos } \\
\text { projetos; (4) As metodologias construídas de certificação socioambiental e de desenvolvimento local } \\
\text { participativo são replicadas, a partir de um processo sistematizado de aprendizado, por parte das } \\
\text { organizações receptoras; as metodologias são difundidas em diversas publicações, priorizando } \\
\text { públicos com pouco acesso a informação; (5) Estabelecimento de parcerias com órgãos ambientais } \\
\text { nos níveis federal e também projetos colaborativos com prefeituras locais e universidades, em prol }\end{array}$ \\
\hline
\end{tabular}


Grounded Theory com Utilização do Software Atlas.Ti: Um Exemplo Empírico de Estudo sobre Estratégia de Ascensão do Empreendedorismo Inovador em Negócios Sociais

\begin{tabular}{|c|c|}
\hline & $\begin{array}{l}\text { da conservação das florestas; representação no Conselho Consultivo do Fundo Nacional de } \\
\text { Desenvolvimento Florestal; participação em discussões públicas na Câmara e no Senado, com vistas } \\
\text { à formulação de propostas sobre Códigos florestais; coordenação de um processo nacional para a } \\
\text { definição de salvaguardas socioambientais a projetos de Redução das Emissões por Desmatamento e } \\
\text { Degradação florestal (REDD), que foi, posteriormente, incorporado pelo Governo Federal; o método } \\
\text { foi sistematizado e tem sido replicado em países da África; o empreendedor social participou da } \\
\text { elaboração e implementação da Lei Nacional de Gestão de Florestas Públicas, influenciou } \\
\text { diretamente a criação de um mosaico de florestas estaduais no Pará e exerce influência sobre as } \\
\text { legislações municipais. }\end{array}$ \\
\hline $\begin{array}{l}\text { 5.2 Descrição do } \\
\text { negócio social } \\
\text { Educar.docx }\end{array}$ & $\begin{array}{l}\text { (1) Além de repasses governamentais, são estabelecidas parcerias com a iniciativa privada e } \\
\text { associações para potencializar a fonte própria futura; busca-se profissionalização contínua da gestão } \\
\text { e mecanismos sucessórios e de descentralização das decisões são implantado e destaca-se o } \\
\text { estabelecimento recente de um conselho de administração; (2) Atuação direta nas comunidades do } \\
\text { Rio de Janeiro e, em 2008, a metodologia Mandala dos Saberes assumiu alcance nacional e foi } \\
\text { implantada na rede de } 10.042 \text { escolas ligadas ao Programa Federal Mais Educação; em anos } \\
\text { recentes, a metodologia Pontos de Cultura foi aplicada também em cinco cidades brasileiras (Belém, } \\
\text { Brasília, Porto Alegre, Recife e Rio de Janeiro); (3) A iniciativa beneficia diretamente cerca de } 360 \\
\text { crianças e adolescentes por ano; o projeto também atinge de forma indireta cerca de } 2.000 \\
\text { indivíduos; ao longo dos anos, foram realizados } 23 \text { projetos, com } 16 \text { empresas parceiras, cinco } \\
\text { órgãos governamentais apoiadores, atingindo diretamente } 5.200 \text { crianças e, indiretamente, outros } 19 \\
\text { mil jovens; (4) As metodologias sociais são desenvolvidas e testadas nas unidades centrais de } \\
\text { Mangueira e de Macacos, em seguida, são convertidas em publicações que auxiliam a replicação; } \\
\text { são também desenvolvidos seminários de formação para professores e são organizados fóruns } \\
\text { virtuais de forma que cada escola possa construir projetos pedagógicos customizados; (5) As } \\
\text { parcerias governamentais e a disseminação das metodologias desenvolvidas influenciam as políticas } \\
\text { nacionais da rede pública de ensino; a empreendedora social também participa de debates, engaja-se } \\
\text { em redes de gestores de ensino e professores e lança livros relatando suas experiências. }\end{array}$ \\
\hline $\begin{array}{l}\text { 6.2 Descrição do } \\
\text { negócio social } \\
\text { Noos.docx }\end{array}$ & $\begin{array}{l}\text { (1) Patrocínios e geração própria de recursos, advindos das mensalidades dos cursos, das vendas de } \\
\text { publicações, dos honorários por palestras e das sublocações de salas da escola para o atendimento de } \\
\text { psicólogos; ressaltando-se, ainda, que a organização tem conseguido custear parte de sua estrutura } \\
\text { fixa por meio de taxas de administração dos projetos, por isso, a geração própria de receita chega a } \\
67 \% \text { do orçamento; (2) A experiência nasceu na cidade do Rio de Janeiro, onde realiza o } \\
\text { atendimento direto de cerca de } 400 \text { pessoas por mês, abarcando } 15 \text { municípios cariocas; foram } \\
\text { realizadas, também, capacitações e palestras em } 12 \text { municípios brasileiros e dois municípios de } \\
\text { Portugal; (3) Estima-se que foram diretamente beneficiadas } 2.845 \text { pessoas; (4) Sistematização das } \\
\text { experiências e difusão a partir de publicações; (5) A metodologia criada de grupos reflexivos de } \\
\text { gênero influenciou a Lei Maria da Penha; é referência de capacitação em terapia comunitária no } \\
\text { Estado do Rio de Janeiro; atuação nas discussões que tornaram a terapia comunitária política pública } \\
\text { nacional e também na aprovação da chamada Lei da Palmada, que estabelece o direito da criança e } \\
\text { do adolescente de serem educados sem palmadas e beliscões. }\end{array}$ \\
\hline
\end{tabular}

Figura 5 - Citações selecionadas e recuperados a partir do menu “code < code manager $>$ ” do ATLAS.ti Fonte: Adaptado de Costa e Itelvino (2016)

Avançando com a codificação aberta, no projeto didático considerado "empreendedorismo social para inovação social", as propriedades foram agrupadas em categorias conceituais, que fundamentaram o fenômeno investigado, como forma de dimensionar e reduzir a extensão dos dados brutos.
Como exemplo, destaca-se a categoria "interesses do empreendedor social" (no ATLAS.ti, representada por “CODES"), que decorreu da intepretação e agrupamento de 16 propriedades aderentes, conforme descrito no relatório gerado a partir do menu "code < code manager >", do ATLAS.ti (Figura 6). 
Grounded Theory com Utilização do Software Atlas.Ti: Um Exemplo Empírico de Estudo sobre Estratégia de Ascensão do Empreendedorismo Inovador em Negócios Sociais

\begin{tabular}{l}
\hline Report: 16 quotation(s) for 1 code "Interesses" \\
P1: 4.3 Depoimentos de indivíduos impactados_Imaflora.docx - 12 \\
(1) promove o ser humano a ser melhor e viver bem \\
P10: 4.1 História de vida do empreendedor_Imaflora.docx - 10:31 \\
(2) paixão pelo contato com a natureza \\
P 9: 3.3 Depoimentos de indivíduos impactados_Geekie.docx - 9:2 \\
(3) Hoje sou acadêmico e sonho fazer mestrado e doutorado \\
P 1: 1.1 História de vida do empreendedor_Cren.docx - 1:11 \\
(4) querer saber o porquê das coisas
\end{tabular}

P12: 4.3 Depoimentos de indivíduos impactados_Imaflora.docx - 12:4

(5) com a certificação, passaram a se dar mais valor

P 1: 1.1 História de vida do empreendedor_Cren.docx - 1:22

(6) vontade de ajudar

MEMO:

Marco do primeiro trabalho no âmbito social e do ideal de transformação social.

P 7: 3.1 História de vida do empreendedor_Geekie.docx - 7:32

(7) onepay, onefree

P 1: 1.1 História de vida do empreendedor_Cren.docx - 1:24

(8) desejo de transformação

MEMO:

Marco do primeiro trabalho no âmbito social e do ideal de transformação social.

P 9: 3.3 Depoimentos de indivíduos impactados_Geekie.docx - 9:3

(9) Quero ser um pesquisador e ajudar muitas pessoas

P 1: 1.1 História de vida do empreendedor_Cren.docx - 1:26

(10) questionamentos em tempo integral

P10: 4.1 História de vida do empreendedor_Imaflora.docx - 10:35

(11) trabalhar com a natureza e o social

MEMO:

Marco do primeiro trabalho no âmbito social e do ideal de transformação social.

P 1: 1.1 História de vida do empreendedor_Cren.docx - 1:38

(12) oportunidade de voltar para a favela

P12: 4.3 Depoimentos de indivíduos impactados_Imaflora.docx - 12:17

(13) estimula a conservar o meio ambiente e a bater de porta em porta pra que outros possam fazer isso também

P 7: 3.1 História de vida do empreendedor_Geekie.docx - 7:6

(14) descobriram um interesse em comum: a educação

P 1: 1.1 História de vida do empreendedor_Cren.docx - 1:2

(15) respostas transformadoras

P 7: 3.1 História de vida do empreendedor_Geekie.docx - 7:31

(16) a tecnologia criada tinha que ir além, a ponto de acertar a grande massa de estudantes do ensino público

Figura 6 - Categoria "Interesses do Empreendedor Social” (Exemplo) do ATLAS.ti

Fonte: Elaborada pelas autoras

Destaca-se, ainda, que uma dada propriedade (citação no ATLAS.ti), quando de grande relevância para o fenômeno (segundo a interpretação do pesquisador), pode dar origem a um novo código, ou seja, a uma nova categoria conceitual com vistas a fundamentar o fenômeno investigado (Tela 6, Figura 7, em que a propriedade "Políticas Públicas" deu origem a um código com o mesmo nome, a partir do comando "Code in Vivo"). Esses procedimentos de análise são definidos por Strauss e Corbin (1998) como comparações teóricas.
Cabe adicionar que algumas propriedades (“QUATATIONS”) evidenciaram a interação de dois ou mais códigos (Telas da Figura 7), na qual "Motivação" ("CODE 1") e "Educação Formal" ("CODE 2") coocorreram em um mesmo fragmento de texto, a saber: [Esse misto de paixão pelo ser humano e de questionamentos em tempo integral (código "Motivação")a levou para o curso de psicologia. Passou na USP (Universidade de São Paulo)" (código “Educação Formal”)”]. 
Grounded Theory com Utilização do Software Atlas.Ti: Um Exemplo Empírico de Estudo sobre Estratégia de Ascensão do Empreendedorismo Inovador em Negócios Sociais

\section{Telas e Comando do ATLAS TI}

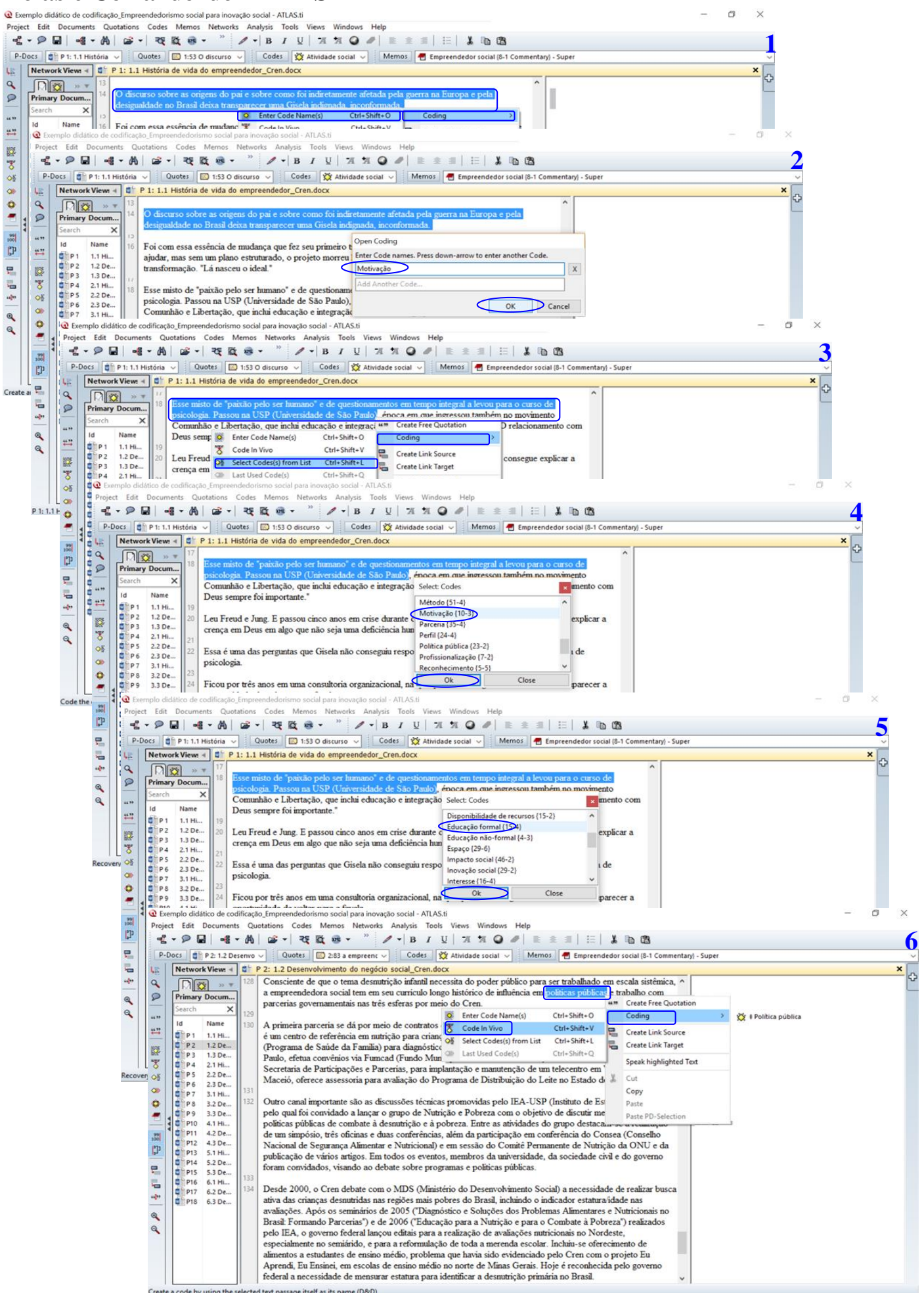

Tela $1<$ Clique com o botão direto do mouse sobre a citação selecionada $\rangle\langle$ Enter Code Name(s) $\rangle\langle$ Coding $\rangle$; Tela 2 <inserir nome do código $\rangle\langle\mathrm{OK}\rangle$; Tela $3<$ Clique com o botão direto do mouse sobre a citação selecionada $\rangle\langle$ Coding $\rangle$ $<$ Select Codes(s) from List>; Tela 4 <Seleção do CODE Motivação〉< 〈OK〉; Tela $5<$ Seleção do CODE Educação fomal>

$\langle\mathrm{OK}\rangle$; Tela 6 <Clique com o botão direto do mouse sobre a citação selecionada > Coding > <Code in Vivo $\rangle$.

Figura 7 - Identificação de categorias (codificação aberta), representadas no ATLAS.ti por "CODES" Fonte: Elaborada pelas autoras 
Grounded Theory com Utilização do Software Atlas.Ti: Um Exemplo Empírico de Estudo sobre Estratégia de Ascensão do Empreendedorismo Inovador em Negócios Sociais

É importante frisar que, uma vez criados os códigos "Motivação" e "Educação Formal” (Telas 1 e 2, Figura 7), eles foram recuperados a partir do comando "Select Codes(s) from List" (Telas 3, 4 e 5, Figura 7) e, então, associados às propriedades aderentes (citações), identificadas, subsequentemente, nos dados brutos, aumentando o grau de fundamentação dos códigos. Esses procedimentos de análise são definidos por Strauss e Corbin (2008) como comparações incidente-incidente e contribuem para o aumento da fundamentação dos códigos.

A propósito, esclarece-se que, no ATLAS.ti, os códigos possuem dois números de referência: o primeiro se refere à quantidade de citações ligadas a ele, sendo uma evidência de grau de fundamentação teórica para cada código; e o segundo ao número de vínculos que um dado código estabelece com outros códigos, sendo uma evidência de grau de densidade para um nó (código), quando é proposta uma visão de rede. A partir do menu "code<code manager>", é possível acessar a lista completa de códigos, bem como verificar para um o grau de fundamentação, de densidade, as datas de criação e modificação.

Por fim, são representados no Gráfico 1 os códigos gerados, bem como o número de citações vinculadas, sendo, portanto, uma evidência do grau de fundamentação de cada código e do grau acumulado de fundamentação da teoria substantiva, gerada a partir dos dados empíricos (área azul projetada no Gráfico 1).

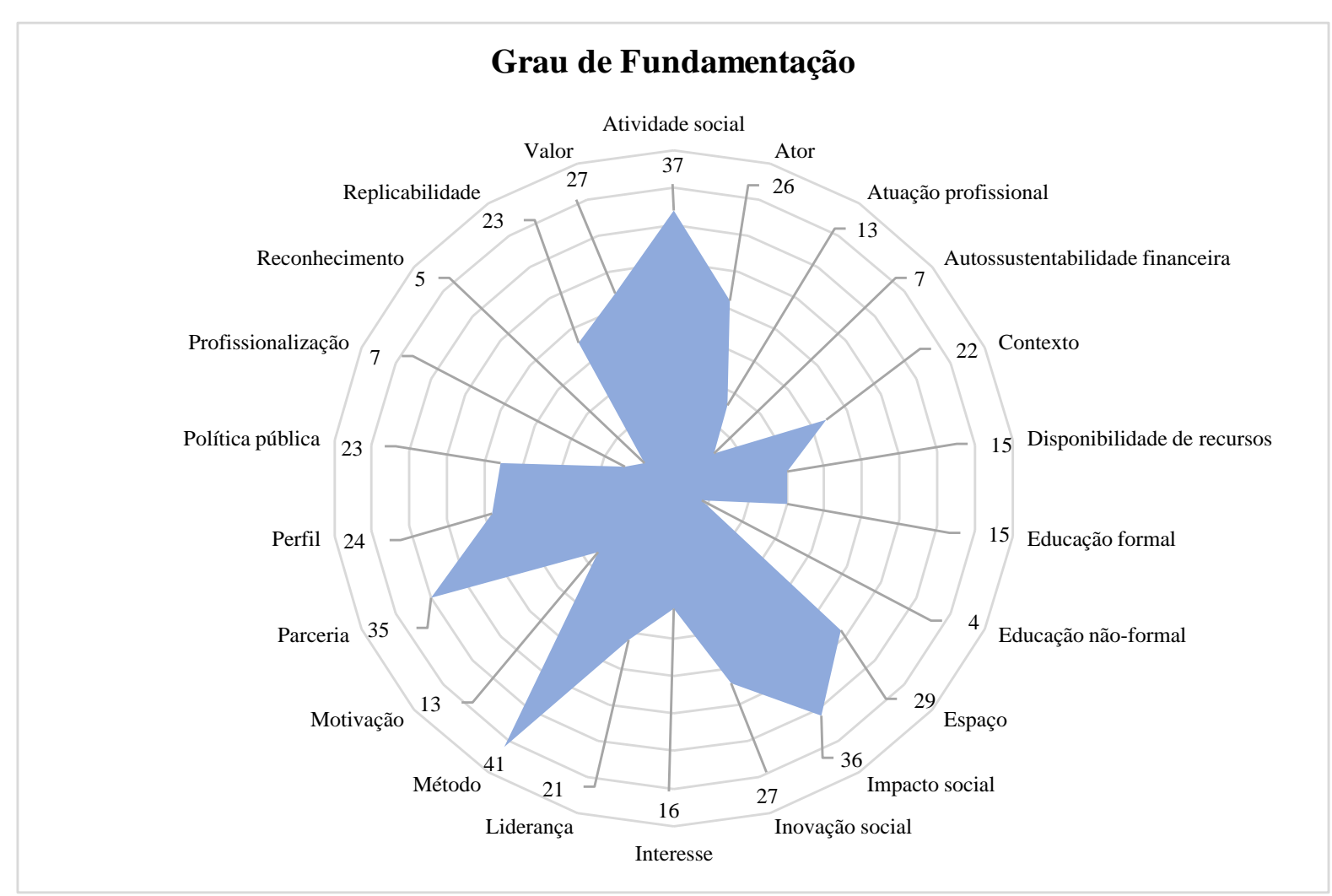

Gráfico 1 - Grau de fundação dos códigos.

Fonte: Elaborada pelas autoras

\section{Codificação axial}

À medida que as categorias conceituais do fenômeno surgiram do fluxo de comparações contínuas e sucessivas, elas foram reagrupadas e relacionadas em famílias (representada por "CODE FAMILY", no ATLAS.ti), de forma a expressar, ao final da codificação, o contexto, as condições, as estratégias de ação e as consequências do fenômeno (codificação axial). Sendo assim, nesse projeto didático de codificação, as categorias conceituais do fenômeno investigado foram geradas a partir da composição das famílias de códigos e seus relacionamentos (número de vínculos dos códigos).

Para agrupar os códigos (categorias) em famílias de códigos (grupos de categorias), foram adotadas ferramentas de busca do ATLAS.ti, de forma a recuperar e analisar, subsequentemente, as citações (propriedades) de cada código e de códigos tomados conjuntamente. 
Grounded Theory com Utilização do Software Atlas.Ti: Um Exemplo Empírico de Estudo sobre Estratégia de Ascensão do Empreendedorismo Inovador em Negócios Sociais

Recuperou-se, então (Figura 8, Telas 1, 2 e 3), 466 citações vinculadas aos 22 códigos gerados. Buscas mais complexas mapearam as interações entre códigos; para tanto, adotou-se operadores booleanos (“AND", “OR", AND "NOT"), tendo sido recuperadas (Figura 8, Telas 4 e 5) 51 citações, para a busca conjunta dos códigos "contexto" e "espaço". Utilizou-se, ainda, os operadores de proximidade, a fim de analisar as relações espaciais (por exemplo, distância, incorporação, sobreposição e coocorrência) entre segmentos de dados codificados (Tela 6, Figura 10), sendo assim, foi possível identificar a coocorrência de 6 citações para os códigos "inovação social" e "métodos".

Além das ferramentas de busca (Figura 8), analisou-se também a tabela de coocorrência de todos os códigos, como evidência para agrupá-los em famílias de códigos. Como representado a seguir, foi gerada, inicialmente, a partir do ATLAS.ti, a tabela de coocorrência com todos os códigos, evidenciando a presença de unidades linguísticas (citações, ou seja, fragmentos de texto que deram significado ao fenômeno) que ocorreram, simultaneamente, em um mesmo contexto de análise.

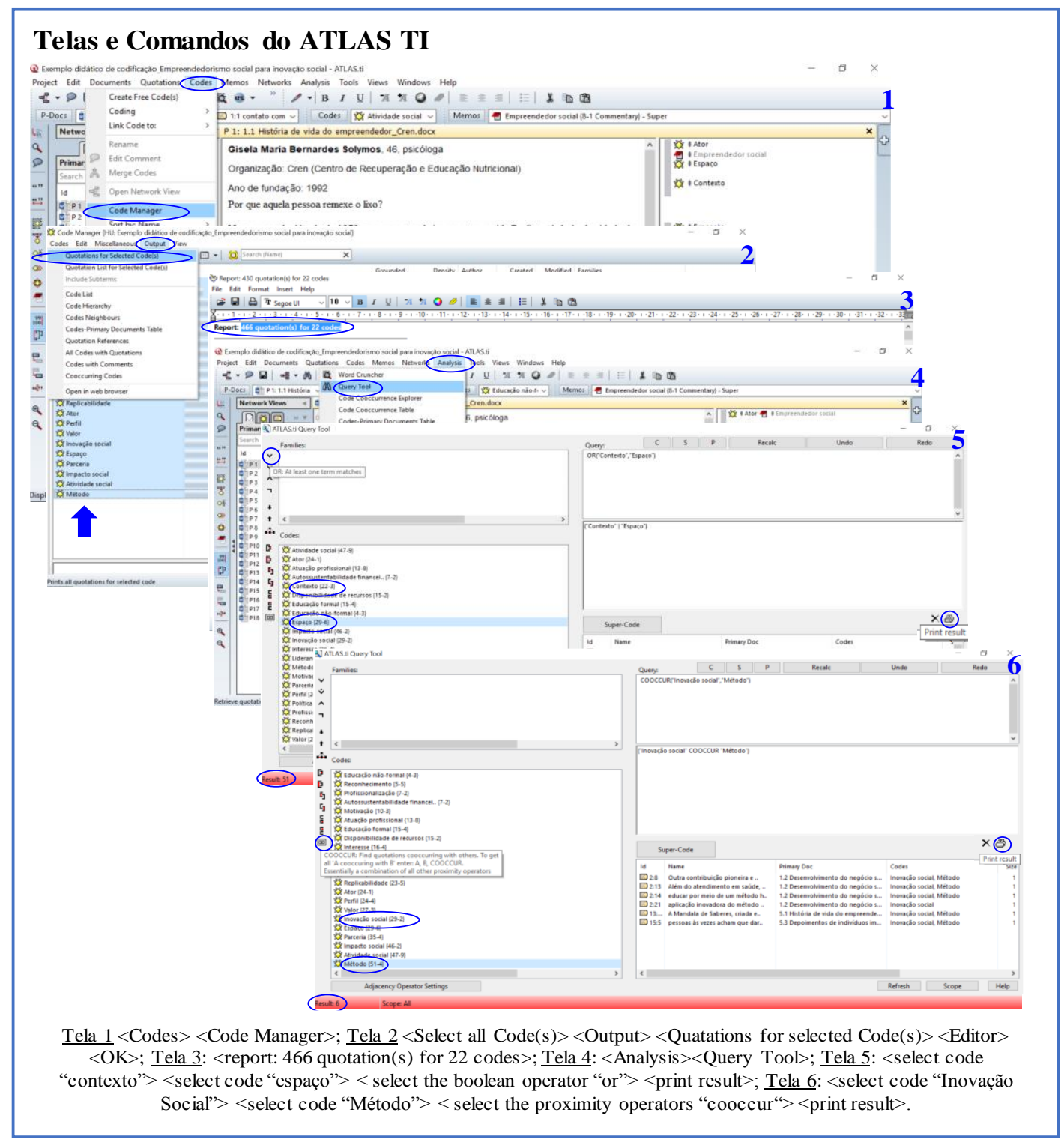

Figura 8 - Comandos de recuperação e cruzamento de dados do ATLAS.ti, usados para agrupar os códigos em famílias de dados

Fonte: Elaborada pelas autoras 
Grounded Theory com Utilização do Software Atlas.Ti: Um Exemplo Empírico de Estudo sobre Estratégia de Ascensão do Empreendedorismo Inovador em Negócios Sociais

Sendo assim, agrupou-se os códigos, levando em consideração os seus maiores níveis de coocorrência (células em azul, na Tabela 1): na coluna 1, o maior nível de coocorrência se deu entre os códigos "atividade social" e "contexto" $(0,06)$, sendo, portanto, analisados, mediante recuperação dos dados brutos e, subsequentemente, agrupados de acordo com a ocorrência simultânea de unidades linguísticas em um mesmo contexto de análise. Ressalta-se que, para as demais colunas o mesmo procedimento de análise foi adotado, totalizando, ao final, 6 agrupamentos, ou seja, 6 famílias (Tabela 1).

Tabela 1 - Coocorrência dos códigos.

\begin{tabular}{|c|c|c|c|c|c|c|c|c|c|c|c|c|c|c|c|c|c|c|c|c|c|c|c|}
\hline Códigos & 1 & 2 & 3 & 4 & 5 & 6 & 7 & 8 & 9 & 10 & 11 & 12 & 13 & 14 & 15 & 16 & 17 & 18 & 19 & 20 & 21 & 22 & $\begin{array}{c}\text { coocorrência } \\
\text { dos códigos }\end{array}$ \\
\hline 1 Atividade social & 0 & 0 & 0 & 0 & 0,06 & 0 & 0 & 0,02 & 0 & 0,01 & 0 & 0 & 0 & 0,04 & 0 & 0,05 & 0 & 0,01 & 0 & 0 & 0 & 0 & 0,19 \\
\hline 2 Ator & 0 & 0 & 0 & 0 & 0 & 0 & 0,03 & 0 & 0 & 0 & 0 & 0,04 & 0 & 0,01 & 0 & 0 & 0 & 0 & 0 & 0 & 0 & 0 & 0,08 \\
\hline 3 Atuação profissional & 0 & 0 & 0 & 0 & 0 & 0 & 0,04 & 0 & 0,05 & 0 & 0 & 0 & 0 & 0 & 0 & 0 & 0,03 & 0 & 0 & 0 & 0 & 0 & 0,12 \\
\hline 4 Autossustentabilidade financeira & 0 & 0 & 0 & 0 & 0 & 0,22 & 0 & 0 & 0 & 0 & 0 & 0 & 0 & 0 & 0 & 0,02 & 0 & 0 & 0,08 & 0 & 0 & 0 & 0,32 \\
\hline 5 Contexto & 0,06 & 0 & 0 & 0 & 0 & 0 & 0 & 0 & 0 & 0 & 0,02 & 0 & 0,02 & 0,01 & 0 & 0,02 & 0 & 0 & 0 & 0 & 0,02 & 0 & 0,15 \\
\hline 6 Disponibilidade de recursos & 0 & 0 & 0 & 0,22 & 0 & 0 & 0 & 0 & 0 & 0 & 0 & 0 & 0 & 0,02 & 0 & 0,09 & 0 & 0,06 & 0,05 & 0 & 0,03 & 0 & 0,47 \\
\hline 7 Educação formal & 0 & 0,03 & 0,04 & 0 & 0 & 0 & 0 & 0 & 0,05 & 0 & 0 & 0 & 0 & 0 & 0 & 0 & 0,03 & 0 & 0 & 0 & 0 & 0,02 & 0,17 \\
\hline 8 Educação não-formal & 0,02 & 0 & 0 & 0 & 0 & 0 & 0 & 0 & 0 & 0 & 0 & 0 & 0 & 0 & 0,08 & 0 & 0 & 0 & 0 & 0 & 0 & 0 & 0,1 \\
\hline 9 Espaço & 0 & 0 & 0,05 & 0 & 0 & 0 & 0,05 & 0 & 0 & 0 & 0 & 0 & 0,02 & 0 & 0 & 0 & 0 & 0 & 0 & 0 & 0 & 0,02 & 0,14 \\
\hline 10 Impacto social & 0,01 & 0 & 0 & 0 & 0 & 0 & 0 & 0 & 0 & 0 & 0 & 0 & 0 & 0 & 0 & 0 & 0 & 0 & 0 & 0 & 0 & 0 & 0,01 \\
\hline 11 Inovação social & 0 & 0 & 0 & 0 & 0,02 & 0 & 0 & 0 & 0 & 0 & 0 & 0 & 0,04 & 0,08 & 0 & 0 & 0 & 0 & 0 & 0 & 0 & 0 & 0,14 \\
\hline 12 Interesse & 0 & 0,04 & 0 & 0 & 0 & 0 & 0 & 0 & 0 & 0 & 0 & 0 & 0 & 0 & 0 & 0 & 0 & 0 & 0 & 0 & 0 & 0 & 0,04 \\
\hline 13 Liderança & 0 & 0 & 0 & 0 & 0,02 & 0 & 0 & 0 & 0,02 & 0 & 0,04 & 0 & 0 & 0,04 & 0,03 & 0,02 & 0,02 & 0,02 & 0 & 0,03 & 0 & 0 & 0,24 \\
\hline 14 Método & 0,04 & 0,01 & 0 & 0 & 0,01 & 0,02 & 0 & 0 & 0 & 0 & 0,08 & 0 & 0,04 & 0 & 0 & 0,05 & 0 & 0,04 & 0 & 0 & 0,04 & 0 & 0,33 \\
\hline 15 Motivação & 0 & 0 & 0 & 0 & 0 & 0 & 0 & 0,08 & 0 & 0 & 0 & 0 & 0,03 & 0 & 0 & 0 & 0 & 0 & 0 & 0 & 0 & 0 & 0,11 \\
\hline 16 Parceria & 0,05 & 0 & 0 & 0,02 & 0,02 & 0,09 & 0 & 0 & 0 & 0 & 0 & 0 & 0,02 & 0,05 & 0 & 0 & 0 & 0,18 & 0 & 0 & 0,12 & 0 & 0,55 \\
\hline 17 Perfil & 0 & 0 & 0,03 & 0 & 0 & 0 & 0,03 & 0 & 0 & 0 & 0 & 0 & 0,02 & 0 & 0 & 0 & 0 & 0 & 0 & 0,02 & 0 & 0 & 0,1 \\
\hline 18 Política pública & 0,01 & 0 & 0 & 0 & 0 & 0,06 & 0 & 0 & 0 & 0 & 0 & 0 & 0,02 & 0,04 & 0 & 0,18 & 0 & 0 & 0,07 & 0,04 & 0,02 & 0 & 0,44 \\
\hline 19 Profissionalização & 0 & 0 & 0 & 0,08 & 0 & 0,05 & 0 & 0 & 0 & 0 & 0 & 0 & 0 & 0 & 0 & 0 & 0 & 0,07 & 0 & 0 & 0 & 0 & 0,2 \\
\hline 20 Reconhecimento & 0 & 0 & 0 & 0 & 0 & 0 & 0 & 0 & 0 & 0 & 0 & 0 & 0,03 & 0 & 0 & 0 & 0,02 & 0,04 & 0 & 0 & 0,04 & 0 & 0,13 \\
\hline 21 Replicabilidade & 0 & 0 & 0 & 0 & 0,02 & 0,03 & 0 & 0 & 0 & 0 & 0 & 0 & 0 & 0,04 & 0 & 0,12 & 0 & 0,02 & 0 & 0,04 & 0 & 0 & 0,27 \\
\hline 22 Valor & 0 & 0 & 0 & 0 & 0 & 0 & 0,02 & 0 & 0,02 & 0 & 0 & 0 & 0 & 0 & 0 & 0 & 0 & 0 & 0 & 0 & 0 & 0 & 0,04 \\
\hline $\begin{array}{l}\text { Intensidade acumulada de } \\
\text { coocorrência dos códigos }\end{array}$ & 0,19 & 0,08 & 0,12 & 0,32 & 0,15 & 0,47 & 0,17 & 0,1 & 0,14 & 0,01 & 0,14 & 0,04 & 0,24 & 0,33 & 0,11 & 0,55 & 0,1 & 0,44 & 0,2 & 0,13 & 0,27 & 0,04 & 4,34 \\
\hline Agrupamentos & G1 & $\mathrm{G} 2$ & $\mathrm{G} 3$ & $\mathrm{G} 4$ & G1 & $\mathrm{G} 4$ & G3 & G3 & $\mathrm{G} 3$ & G1 & G5 & $\mathrm{G} 2$ & G5 & G5 & $\mathrm{G} 3$ & G6 & G3 & G6 & $\mathrm{G} 4$ & G6 & G6 & G3 & TOTAL DE 6 \\
\hline
\end{tabular}

Legenda: Telas e comando do ATLAS.ti para geração da coocorrência: Tela $1<$ Analysis $><$ Code CooccurrenceTable $>$; Tela 2: $\langle$ select the codes for the columns $\rangle\langle$ select the codes for the rows $\rangle\langle$ Export the table in Excel delimitedformat $>$; Tela 3 : $\langle$ file $>\langle\mathrm{OK}\rangle$.

Fonte: Elaborada pelas autoras.

Depois de agrupados os códigos em famílias, considerando os maiores níveis de coocorrência, adotou-se o comando de Networks, do ATLAS.ti, para a análise exploratória das estruturas e das relações dos códigos, de forma que eles pudessem representar o fenômeno, o contexto, as condições, as estratégias e as consequências, conforme recomendam Strauss e Corbin (2008) na metodologia Grounded Theory.

Cabe explicar que, no ATLAS.ti, tem-se uma "visão de rede" dos códigos, ou seja, de um conjunto de nós (códigos) e de seus vínculos (setas), sendo que cada nó pode ser vinculado a um número arbitrário de outros nós, dependendo das relações identificadas no decorrer do fluxo de comparações contínuas e sucessivas, realizadas decorrerão longo das codificações. O número de vínculos (setas) para qualquer um dos nós (códigos) é chamado de grau.
Outra propriedade da visão de rede é a sua ordem, ou seja, o número de nós (códigos).

Sendo assim, no exemplo didático de codificação, os 22 códigos e seus agrupamentos por coocorrência (indicados em 6 cores na Figura 9) foram, então, representados em uma visão de rede, a saber: Grupo 1 (G1) e seus códigos (1) Atividade social, (2) Contexto e (3) Impacto social; Grupo 2 (G2) e seus códigos (4) Ator e (5) Interesse; Grupo 3 (G3) e seus códigos (6) Atuação profissional, (7) Educação formal, (8) Educação não-formal, (9) Espaço, (10) Motivação,(11) Perfil e (12) Valor; Grupo 4 (G4) e seus códigos (13) Autossustentabilidade financeira,

Disponibilidade de recursos e (15) Profissionalização; Grupo 5 (G5) e seus códigos (16) Inovação social (17) Liderança e (18) Método; 
Grounded Theory com Utilização do Software Atlas.Ti: Um Exemplo Empírico de Estudo sobre Estratégia de Ascensão do Empreendedorismo Inovador em Negócios Sociais

e, por fim, Grupo 6 (G6) e seus códigos

Parceria, (20) Política pública,

Reconhecimento e (22) Replicabilidade.

Para gerar a visão de rede destes 6 agrupamentos (Figura 9), adotou-se o comando "new network view" do ATLAS.ti. Os vínculos entre os códigos (nós) foram representados por setas, para indicar as relações evidenciadas a partir de comparações contínuas e sucessivas, a saber: "is associated with"; "is property of"; "is context for"; "is intervening condition for"; "is strategy for"; "is causal condition for" e "is consequence of" (Figura 9). Sendo assim, foi possível constatar que a visão de rede gerada assumiu uma ordem de 22 nós (número de códigos) e grau acumulado de 42 (número de vínculos), destacando-se o Grupo 3 (na cor branca), com grau acumulado de 17 (evidência de vínculos com outros códigos).

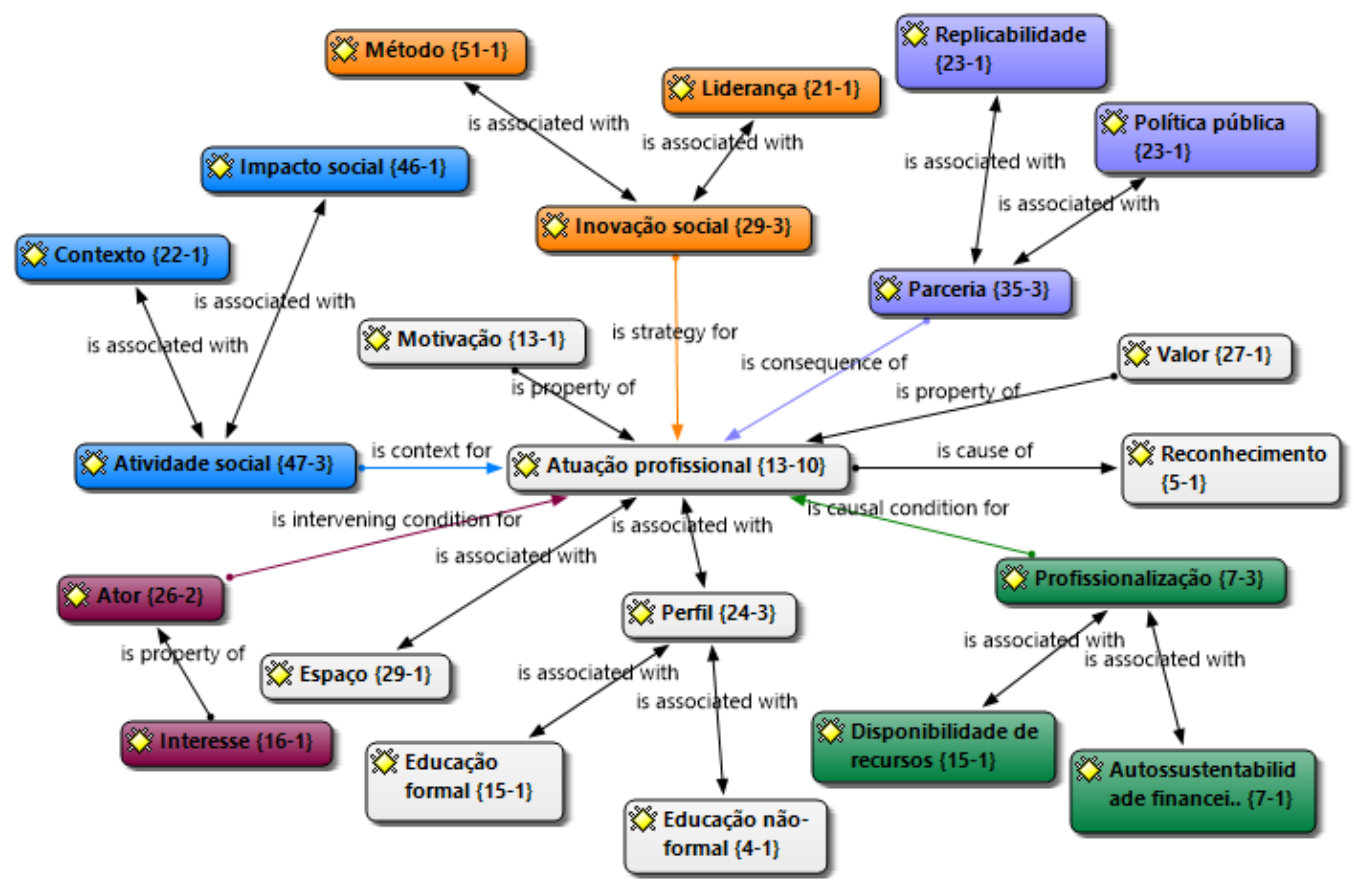

Figura 9 - Visão de rede do agrupamento dos códigos e famílias

Legenda: Grupo 1, na cor azul; Grupo 2, na cor vermelha; Grupo 3 (G3), na cor branca; Grupo 4(G4), na cor verde; Grupo 5 (G5), na cor laranja; e Grupo 6 (G6), na cor roxa.

Fonte: Elaborada pelas autoras

\section{Codificação Seletiva}

Ainda, com base nos tipos de vínculos representados na visão de rede (Figura 9), adotou-se um grau mais elevado de abstração, conforme enfatizam
Strauss e Corbin (2008), na fase de codificação seletiva da metodologia Grounded Theory, para identificação da categoria central do estudo (no ATLAS.ti. representada por super família de códigos, conforme comandos ilustrados na figura 10). 
Grounded Theory com Utilização do Software Atlas.Ti: Um Exemplo Empírico de Estudo sobre Estratégia de Ascensão do Empreendedorismo Inovador em Negócios Sociais

\section{Telas e Comandos do ATLAS TI}

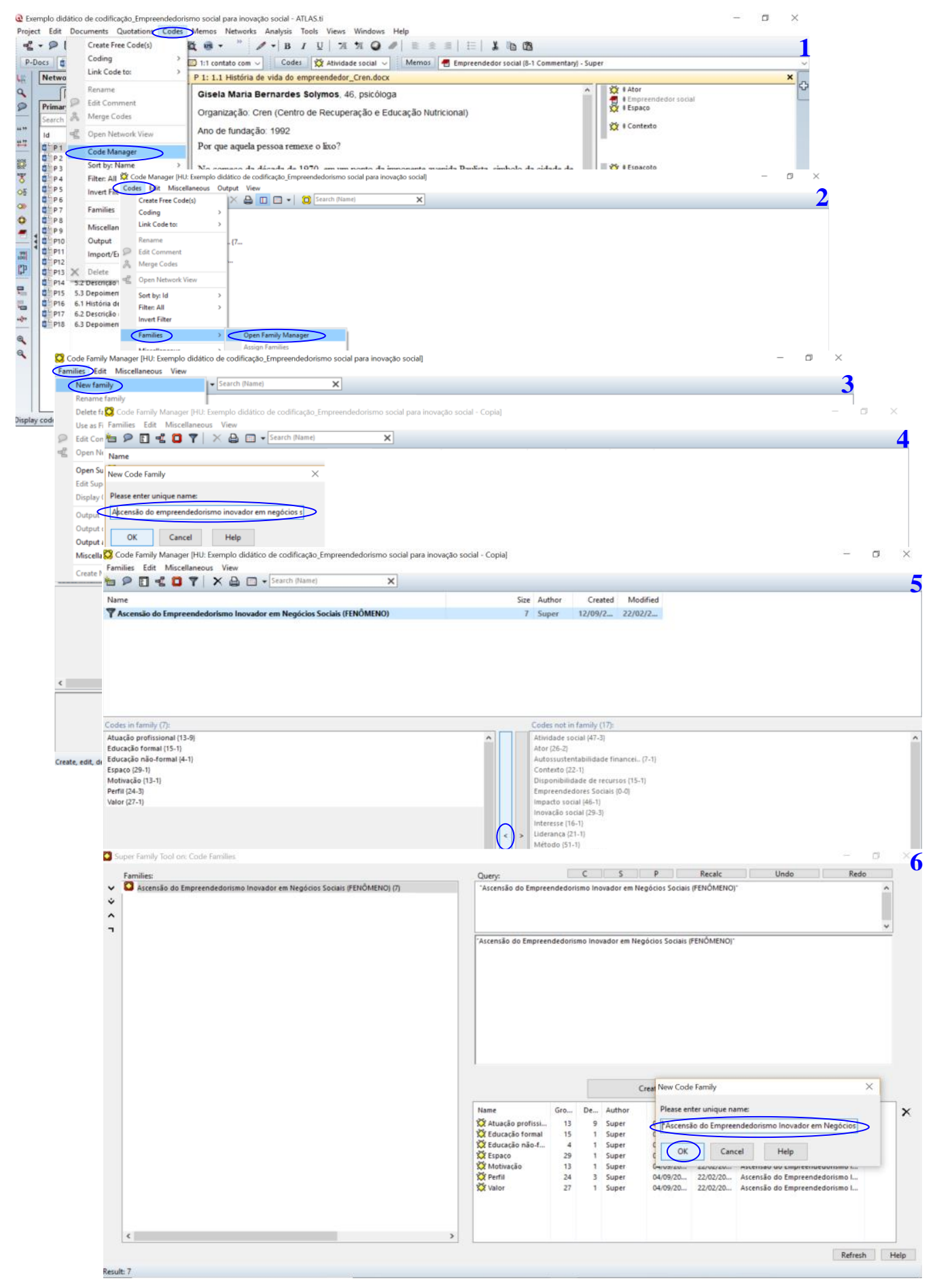

Tela 1 <Codes> <Code Manager>; Tela 2 <Code> <Families><Open Family Manager >; Tela $3<$ Families > <New Family $>$; Tela $4<$ name "Antecedentes Atitudinais" $><\mathrm{OK}>$; Tela 5 <vinculação dos códigos à família "ascensão do empreendedorismo inovador em negócios sociais" usando a "seta"; Tela 6 <Menu Super Family Tool on: Code Families> $<$ duplo click na família "ascensão do empreendedorismo inovador em negócios sociais" $><$ Create Super Family $><$ entrar com o nome da super família> <ok>.

Figura 10 - Categoria central (codificação seletiva), representadas no ATLAS.ti por "super family code" Fonte: Elaborada pelas autoras 
Grounded Theory com Utilização do Software Atlas.Ti: Um Exemplo Empírico de Estudo sobre Estratégia de Ascensão do Empreendedorismo Inovador em Negócios Sociais

Cabe detalhar que os 6 grupos identificados na codificação axial, particularmente na visão de rede (Figura 9), foram, subsequentemente, classificados em categoriais e subcategorias de análise (representado, no ATLAS.ti, pela geração de "families codes", conforme Figura 10).

A categoria central: o Grupo 3 recebeu a classificação de categoria central do estudo, ou seja, aquela que mais explica o fenômeno de "ascensão do empreendedorismo inovador em negócios sociais (AEINS)", com destaque para o código "atuação do empreendedor social" (Figura 11), dado que ele assumiu o ponto de centralidade, na visão de rede (Figura 9) e foi nó receptor do maior número de vínculos: "is associated with"; "is property of"; "is context for"; "is intervening condition for"; "is strategy for"; "is causal condition for"; e "is consequence of".

Os demais grupos (total de 5) foram classificados como subcategorias, nomeadas de: Contexto social (Grupo 1, dado que foi nó de origem da relação “is context for”); Condição interveniente (Grupo 2, pois foi nó de origem da relação "is intervening condition for"); Condição causal (Grupo 4, pois foi nó de origem da relação "is causal condition for"); Estratégia (Grupo 5, pois foi nó de origem da relação "is strategy for") e Consequências (Grupo 6, pois foi nó de origem da relação "is consequence of"').

De forma particularizada, tem-se, na visão de rede, uma representação da categoria central do fenômeno investigado, nomeada de "ascensão do empreendedorismo inovadora em negócios sociais", como forma de ilustrar a construção da teoria substantiva, com base nos dados empíricos: partindo de documentos primários selecionados (extremos da rede), avançou-se para a identificação de significados (citações), associando-os a categorias conceituais (códigos, na cor cinza) que, por fim, foram agrupados e relacionados em uma visão de rede, que evidenciou o nó de centralidade da teoria (categoria central, devido ao maior número de vínculos) (Figura 11).

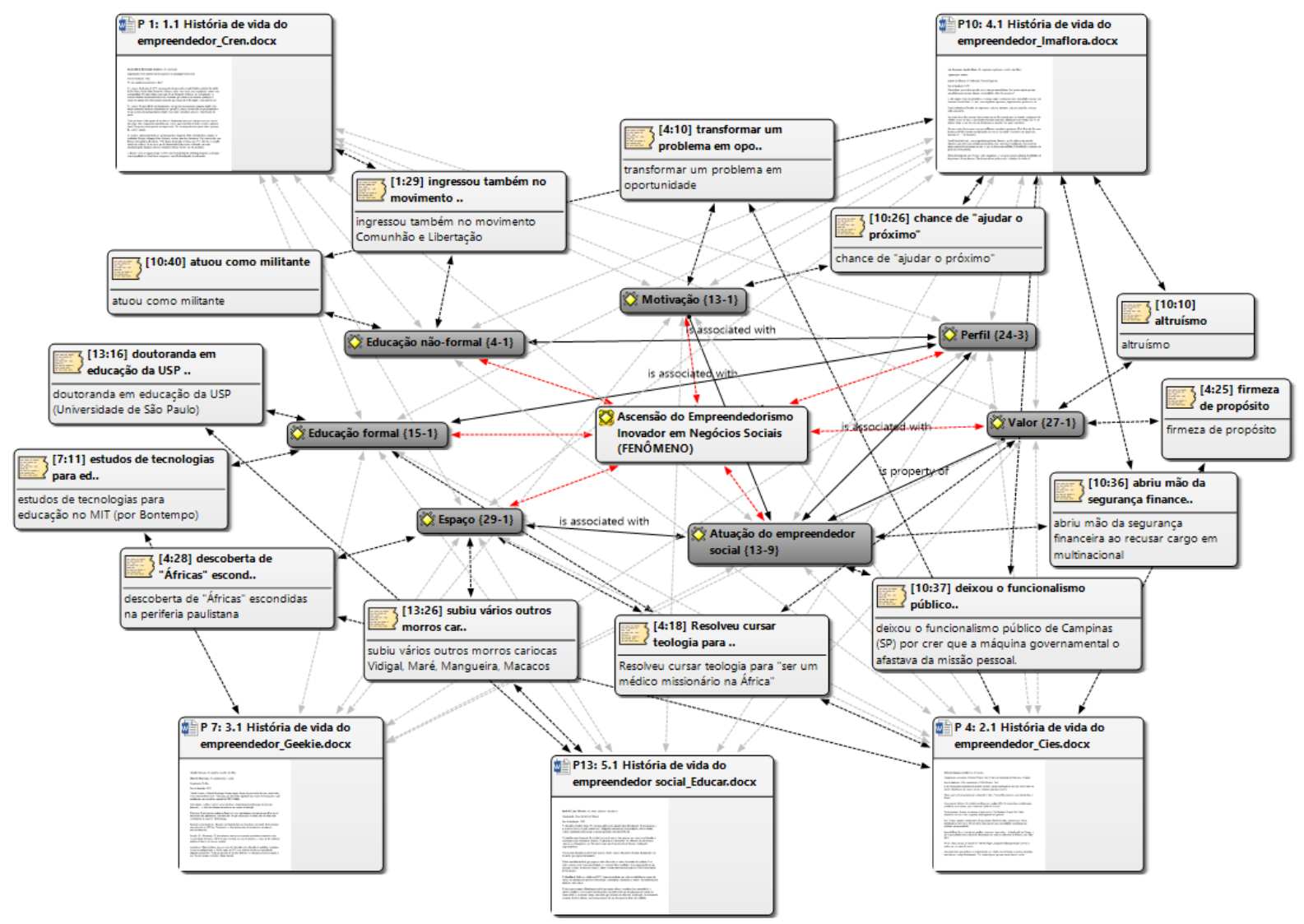

Figura 11 - Visão de rede da categoria central do fenômeno investigado Fonte: Elaborada pelas autoras. 
A visão de rede da categoria central do estudo e suas subcategorias foram validadas em grupo focal, com empreendedores sociais, assumindo, portanto, a forma de teoria substantiva, fundamentada em dados empíricos e validada pelos sujeitos sociais:

- À medida que os empreendedores sociais renovam a suas trajetórias de vida e de liderança, por meio de novos projetos sociais, emergem, portanto, novos contextos e espaços de aprendizagem, muitas vezes coletivos e informais, renovando, assim, as motivações do empreender socialmente. Ao final desse fluxo interdependente e dinâmico de mudanças, tem-se o valor social coletivo, gerado pelo desenvolvimento ou combinação de produtos, processos, ou métodos inovadores, que possibilitaram a melhoria da qualidade de vida do outro e/ou reduziram as desigualdades, derivando em inovações sociais com potencial de replicação em outros contextos e comunidades (Itelvino, Costa, Gohn \& Ramacciotti, 2015, p. 18).

- Pressupõe-se que o produto da inovação social não pode ser analisado isoladamente, pois se deve também compreender a forma como foi processado e gerenciado, contemplando, portanto, produto e processo (Costa \& Itelvino, 2016, p. 14).

- Há prevalência de um contexto cooperativo para resolver questões sociais, enfatizando-se a vinculação permanente e a cooperação entre os atores, com fins de obtenção de mudanças sociais duradouras e de impacto. Isso se dá a partir da diversificação de fontes de recursos, incluindo as usuais (subvenção governamental, doações, parcerias e contratos com empresas, poder público e organizações sociais) e também as emergentes (fonte própria de receita, projetos de captação de recursos e parcerias com instituições de ensino) (Costa \& Itelvino, 2016, p. 14).

- Pressupõe-se que a profissionalização do negócio é uma condição causal da sustentabilidade nas instituições sociais, incluindo sistema de monitoramento, captação de recursos, gestão administrativa e financeira e capacitação técnica dos recursos humanos (Costa \& Itelvino, 2016, p. 14).

- Pressupõe-se a integração sistêmica, as quais abordam a legitimidade e a autonomia dos negócios, bem como a sua rede de parcerias e sua capacidade de ofertar produtos e serviços de impacto social (Costa \& Itelvino, 2016, p. 15).
- Os resultados das inovações sociais são essencialmente intangíveis, associando-se mais à concepção de "serviço", o que torna primordial o estabelecimento de critérios, tanto quantitativos quanto qualitativos, no processo de mensuração dos impactos sociais gerados (Costa \& Itelvino, 2016, p. 16).

- Por fim, pressupõe-se que os negócios de impacto social devem oferecer soluções escaláveis para problemas sociais (Costa \& Itelvino, 2016, p. 16).

Vale, ainda, enfatizar que, a partir dos relatórios do ATLAS.ti, especificamente o gerado no menu "Project $<$ Output $><$ All Objects $>$ ", foi possível consultar todo o roteiro de análise e de interpretação, seguido pelos pesquisadores no decorrer da pesquisa, o que possibilita a auditoria da validade dos resultados por parte dos leitores e demais interessados na pesquisa.

\section{DISCUSSÕES}

Com base nas evidências, contatou-se que os negócios sociais investigados foram criados $\mathrm{e}$ desenvolvidos por empreendedores que geraram transformações sociais, reforçando os preceitos teóricos de Alvord, Brown e Letts (2004), Mair e Ignasi (2006), Austin, Stevenson e Wei-Skillern (2006) e Gohn (2015). Vale também destacar que o desenvolvimento destes negócios demandou a articulação de uma estrutura coletiva para geração de conhecimentos, experiências profissionais e de parcerias que foram cruciais ao desenvolvimento de inovações sociais de impacto, corroborando as discussões de Certo e Miller (2008), Hoogendoorn, Pennings e Thurik (2010), Tondolo, Tondolo e Bitencourt (2013), Sloan, Legrand e Simons (2014).

Observou-se ainda que a formação dos empreendedores sociais assumiu um papel decisivo no que diz respeito à promoção e sustentação dos negócios sociais qualificadores da oferta de produtos e serviços educacionais e da saúde e também na geração de inovações de impacto social, reforçando as reflexões levantadas por Fleury e Fischer (2001), Bandura (2002), Friedlaender (2004), Murphy, Lião e Welsch (2006). Vale destacar que a atuação destes empreendedores foi determinante aos valores coletivos criados, à rede de parceiros estabelecida e aos procedimentos técnicos e interpessoais adotados nos projetos sociais implementados que foram replicados em outras localidades, conforme evidenciaram também as pesquisas de Farfus e 
Rocha (2007), Parente et al. (2011) e Sousa, Bueno, Sousa, e Tech (2013).

Vale destacar o fato de que o processo de formação destes empreendedores sociais deve-se não somente à trajetória de liderança social por eles construída, ou seja, pelo exercício pleno do empreendedorismo social conforme enfatizado também por Yukl, Gordon e Taber (2002), Oliveira (2004) e David (2004), mas foi também um processo resultante dos espaços e contextos de aprendizagem a que esses empreendedores foram submetidos durante suas histórias de vida, bem como por suas motivações individuais de transformação social, corroborando os achados de Minuzzi, Belinazo e Lezana (2005), Macêdo e Boava (2008), Navarro, Climent e Palacio (2011).

\section{CONCLUSÕES}

O objetivo foi explorar como se dá a estratégia de ascensão do empreendedorismo inovador, em negócios sociais, que qualificam a oferta de produtos e serviços educacionais e da saúde. Sobre a abordagem metodológica, foi adotada a pesquisa qualitativa denominada Grounded Theory, fundamentada em dados empíricos. Para tal, foi construído um exemplo didático, com a utilização detalhada do Software ATLAS.ti.

Os resultados demonstraram que o ATLAS.ti pode ser utilizado como apoio às codificações (aberta, axial e seletiva), que fundamentam a Grounded Theory, possibilitando a organização, recuperação e cruzamento de dados e, também, viabilizando a auditoria da validade dos resultados. Para apoiar as análises da Grounded Theory, foram utilizados, ainda, componentes interessantes e característicos do ATLAS.ti (não disponíveis em outros CAQDAS), como Code Cooccurence e Networks, o que facilitou a visualização e interpretação das relações entre categorias e subcategorias norteadoras do fenômeno da ascensão do empreendedorismo inovador em negócios sociais.

Por fim, apresenta-se uma matriz de alinhamento da Grounded Theory, com utilização detalhada do Software ATLAS.ti, considerando como exemplo didático a estratégia de ascensão do empreendedorismo inovador em negócios sociais qualificadores da oferta de produtos e serviços educacionais e da saúde (Figura 12). 


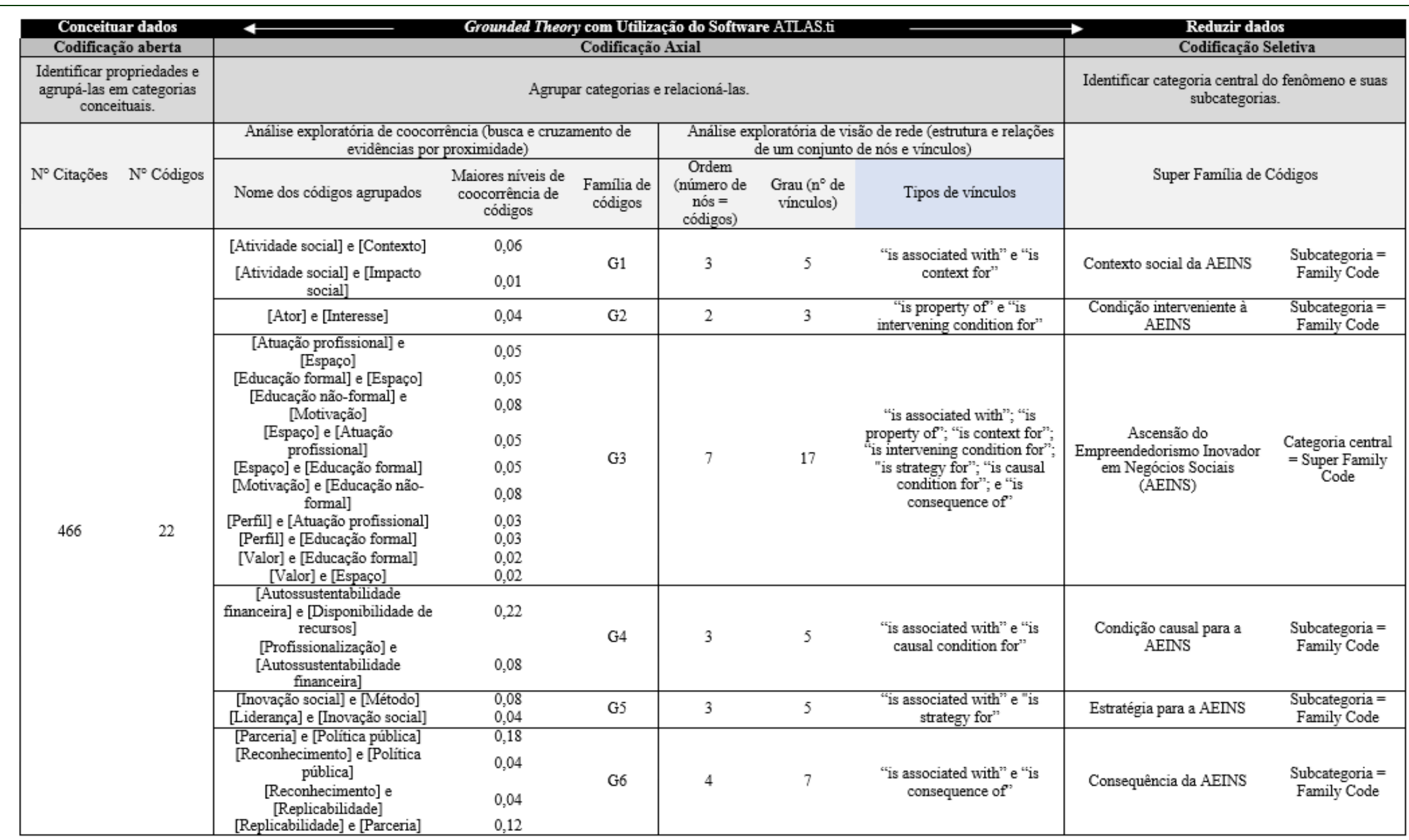

Figura 12 - Matriz de alinhamento da Grounded Theory com utilização detalhada do Software ATLAS.ti Fonte: Elaborada pelas autoras. 
Grounded Theory com Utilização do Software Atlas.Ti: Um Exemplo Empírico de Estudo sobre Estratégia de Ascensão do Empreendedorismo Inovador em Negócios Sociais

\section{REFERÊNCIAS}

Aguiar, L., \& Vasconcellos, L. C. F. D. (2015). A gestão do Sistema Único de Saúde e a Saúde do Trabalhador: o direito que se tem e o direito que se perde. Saúde em Debate, 39: 830-840.

Ahrens, T., \& Chapman, C. S. T. (2007). Doing qualitative fi eld research in management accounting: positioning data to contribute to theory. In: Chapman, C., Hopwood, A. G., \& Shields, M. D. (Org.). Handbook of management accounting research. Amsterdam: Elsevier.

Alvord, S. H., Brown, L. D., \& Letts, C. W. (2004). Social entrepreneurship and societal transformation: an exploratory study. The Journal of Applied Behavioral Science, 40(3), 260-282.

Angot, J., \& Plé, L. (2015). Serving poor people in rich countries: the bottom-of-the-pyramid business model solution. Journal of Business Strategy, 36(2): 3-15.

Austin, J., Stevenson, H., \& Wei-Skillern, J. (2006). Social and Commercial Entrepreneurship: Same, Different, or Both? Entrepreneurship Theory and Practice, 30(1), 1-22.

Bandura, A. (2002). Social cognitive theory in cultural context. International Review, 51(2), 269290.

Bergh, D. D., Aguinis, H., Heavey, C., Ketchen, D. J., Boyd, B. K., Su, P., \& Joo, H. (2016). Using meta-analytic structural equation modeling to advance strategic management research: Guidelines and an empirical illustration via the strategic leadership-performance relationship. Strategic Management Journal, 37(3), 477-497.

Berry, A. J., \& Otley, D. T. (2004). Case-based research in accounting. In: HUMPREY, C.; LEE, Bill. (Org.) The real life guide to accounting research: $a$ behind-the-scenes view of using qualitative research methods. Oxford: Elsevier.

Cajaiba-Santana, G. (2014). Social innovation: Moving the field forward. A conceptual framework. Technological Forecasting and Social Change, 82: 42-51.

Certo, S., \& Miller, T. (2008). Social entrepreneurship: Key issues and concepts. Business Horizons, 51(4), 267- 271.
Charmaz, K. (2009). A construção da teoria fundamentada: guia prático para análise qualitativa. Bookman Editora.

Corbin, J. (2017). Grounded theory. The Journal of Positive Psychology, 12(3): 301-302.

Costa, P. R., \& Itelvino, L. S. (2016). Atuação Sustentável para o Desenvolvimento de Inovações Sociais: Um Estudo com Negócios de Impacto Social. In: XL EnANPAD, Costa do Sauípe.

Dantas, C., Leite, J. L., Lima, S. B. S., \& Stipp, M. A. C. (2009). Teoria fundamentada nos dadosaspectos conceituais e operacionais: metodologia possível de ser aplicada na pesquisa em enfermagem. Revista Latino-Americana de Enfermagem, 17(4): 573-579.

David, D. E. H. (2004). Intra-empreendedorismo social: perspectivas para o desenvolvimento social nas organizações. Tese de Doutorado (Programa de Pós-graduação em Engenharia de Produção) Universidade Federal de Santa Catarina, Florianópolis.

Farfus, D., \& Rocha, M. C. (2007). Inovação Social: um conceito em construção. In: Inovações Sociais, Coleção Inova; vol. II, Curitiba: SESI/SENAI/IEL/UNINDUS.

Farfus, D., \& Rocha, M. C. S. (2007). Inovação Social: um conceito em construção. In: Inovações Sociais, Coleção Inova; vol. II, Curitiba: SESI/SENAI/IEL/UNINDUS.

Fleury, M. T. L., \& Fischer. R. M. (2001). Desenvolver competências e gerir conhecimento em diferentes arranjos empresariais: o caso da indústria brasileira de plásticos. In: Fleury, M. T. L., \& Oliveira Jr., M. de M. (Org.). Gestão estratégica do conhecimento: integrando aprendizagem, conhecimento e competências. São Paulo: Atlas.

Freire, P. (2014). Educação como prática da liberdade. Editora Paz e Terra.

Frezatti, F., Nascimento, A. R., Junqueira, E., \& Sordi Relvas, T. R. (2011). Processo orçamentário: uma aplicação da análise substantiva com utilização da grounded theory. Organizações \& Sociedade, 18(58). 
Grounded Theory com Utilização do Software Atlas.Ti: Um Exemplo Empírico de Estudo sobre Estratégia de Ascensão do Empreendedorismo Inovador em Negócios Sociais

Friedlaender, G. M. S. (2004). Metodologia de Ensino-Aprendizagem visando o Comportamento Empreendedor. Tese (Doutorado em Engenharia de produção) - Programa de Pós-Graduação em Engenharia de Produção da Universidade Federal de Santa Catarina.

Furlanetti, M., \& Barros, N. F. (2013). Construção da Teoria Fundamentada: guia prático para análise qualitativa. Ciência \& Saúde Coletiva, 18(1): 283284.

Gohn, M. G. (2015). Educação não formal no campo das Artes. São Paulo: Cortez.

Hom, P., \& Takacs, K. (2007). Applying advanced panel methods to strategic management research: A tutorial. Research methodology in strategy and management, 4(1)193-272.

Hoogendoorn, B., Pennings, E., \& Thurik, R. (2010). What Do We Know About Social Entrepreneurship? An Analysis of Empirical Research. International Review of Entrepreneurship, 8(2), 1-42.

Itelvino, L. D. S., Costa, P. R. D., Gohn, M. D. G., \& Ramacciotti, C. (2018). Formação do empreendedor social e a educação formal e não formal: um estudo a partir de narrativas de história de vida. Ensaio: Avaliação e Políticas Públicas em Educação, 26(99): 471-504.

Itelvino, L. D. S., Costa, P. R., Gohn, M. D. G. M., Ramacciotti, C., \& Porto, G. S. (2018). Formação Empreendedora Para Geração De Inovações Sociais. Gestão \& Regionalidade, 34(101).

Itelvino, L. S., Costa, P. R., Gohn, M. G. M., Ramacciotti, C. (2015). Formação Empreendedora para Geração de Inovações Sociais: Um Levantamento com Empreendedores Sociais Brasileiros. In: XXXIX Encontro da ANPAD, Belo Horizonte.

Juliani, D. P., Juliani, J. P., Souza, J. A., \& Harger, E. M. (2014). Inovação social: perspectivas e desafios. Revista ESPACIOS, 35(5).

Kolk, A., Rivera-Santos, M., \& Rufin, C. (2014). Reviewing a decade of research on the "base/bottom of the pyramid"(BOP) concept. Business \& Society, 53(3), 338-377.
Lee, R. M., \& Esterhuizen, L. (2000). Computer software and qualitative analysis: trends, issues and resources. International journal of social research methodology, 3(3), 231-243.

Linhares, C. (2017). Experiências instituintes na educação pública? Alguns porquês dessa busca. Revista de Educação Pública, 16(31), 139160.

Macêdo, F. M. F., Boava, D. L. T. (2008). Relação empreendedor e reconhecimento social. In: XI Seminários em Administração. São Paulo.

Mair, J.; \& Ignasi, M. (2006). Social entrepreneurship research: A source of explanation, prediction, and delight. Journal of World Business, 41(1), 36-44.

Minuzzi, J., Belinazo, D. P., \& Lezana, Á. G. R. (2005). As relações entre empreendedorismo e marketing social. As Relações entre Empreendedorismo e Marketing Social. In: II Seminário de Gestão de Negócios. Curitiba.

Mulgan, G., Tucker, S., Ali, R., \& Sanders, B. (2007). Social innovation: what it is, why it matters and how it can be accelerated. Reino Unido, Oxford - Said Business School.

Murphy, P. J., Liao, J., \& Welsch, H. P. (2006). A conceptual history of entrepreneurial thought. Journal of Management History, 12(1), 15-35.

Navarro, A. M., Climent, V. C., Palacio, J. R. S. (2011). Emprendimiento social y empresas de inserción en España. Aplicación del método delphi para la determinación del perfil del emprendedor y las empresas sociales creadas por emprendedores. Revesco, 106(1), 25-45.

Oliveira, E. M. (2004). Empreendedorismo social no Brasil: atual configuração, perspectivas e desafios notas introdutórias. Revista da FAE, 7(2), 9-18.

Parente, C. et al. (2011). Empreendedorismo social: contributos teóricos para a sua definição. Atas do XIV Encontro Nacional de Sociologia Industrial, das Organizações e do Trabalho Emprego e coesão social: da crise da regulação à hegemonia da globalização.

Phillips, W., Lee, H., Ghobadian, A., O’Regan, N., \& James, P. (2015). Social innovation and social 
Grounded Theory com Utilização do Software Atlas.Ti: Um Exemplo Empírico de Estudo sobre Estratégia de Ascensão do Empreendedorismo Inovador em Negócios Sociais

entrepreneurship: A systematic review. Group \& Organization Management, 40(3), 428-461.

Prahalad, C. K. (2005). A riqueza na base da pirâmide. Porto Alegre: Artmed.

PROSPECTIVA (2015a). Estudo de oportunidades no setor de saúde para negócios focados na população de baixa renda. Recuperado em 20 de setembro, 2017, de

http://www.artemisia.org.br/img/conhecimento/Estudo _Oportunidades_Negocios_em_Saude.pdf

PROSPECTIVA (2015b). Estudo de oportunidades no setor de educação para negócios focados na população de baixa renda. Recuperado em 20 de setembro, 2017, de http://apreender.org.br/wpcontent/uploads/2015/08/Estudo-Oportunidades-deNeg\%C3\%B3cios-em-

Educa\%C3\%A7\%C3\%A3o_Porvir.pdf

Silvestre, B. S. (2014). Capability accumulation, innovation, and technology diffusion: Lessons from a Base of the Pyramid cluster. Technovation, 34(56), 270-283.

Sinkovics, N., Sinkovics, R. R., \& Yamin, M. (2014). The role of social value creation in business model formulation at the bottom of the pyramidimplications for MNEs?. International Business Review, 23(4), 692-707.

Sloan, P., Legrand, W., \& Simons-Kaufmann, C. (2014). A survey of social entrepreneurial community-based hospitality and tourism initiatives in developing economies. A new business approach for industry. Worldwide Hospitality and Tourism Themes, 6(1), 51-61.

Sousa, E. G., Bueno, J. M., Sousa, M. G., \& Tech, L. (2013). O Perfil do Empreendedor Social e Suas Dimensões de Atuação: Um Estudo de Seis Casos no Município de Uberlândia-MG. In: XXXVII Encontro da ANPAD - EnANPAD, Rio de Janeiro/RJ.
Sousa, E., Mendonça, J. M. B., Sousa, M. G., \& Santos, L. T. (2014). O Perfil do Empreendedor Social e Suas Dimensões de Atuação: Seis Casos no Município de Uberlândia-MG. Revista Interdisciplinar de Gestão Social, 3(1).

Sousa, F. D. O. S., Medeiros, K. R. D., Gurgel Júnior, G. D., \& Albuquerque, P. C. D. (2014). Do normativo à realidade do Sistema Único de Saúde: revelando barreiras de acesso na rede de cuidados assistenciais. Ciência \& Saúde Coletiva, 19: 12831293.

Strauss, A., \& Corbin, J. (2008). Pesquisa qualitativa: técnicas e procedimentos para o desenvolvimento de teoria fundamentada. Porto Alegre:

Artmed/Bookman.

Tondolo, R. R. P., Tondolo, V. A. G., \& Bitencourt, C. C. (2013). Correlação entre Elementos do Capital Social e Orientação Empreendedora: Um Estudo Exploratório. Revista Eletrônica de Ciência Administrativa, 12(1), 92-105.

TCU (2014). Relatório Sistêmico de Fiscalização. Recuperado em 20 de setembro, 2017, de 14. Recuperado em 20 de setembro, 2017, de file:///C:/Users/Priscila/Downloads/Relat\%C3\%B3rio \%20Sist \%C3\%AAmico\%20de\%20Fiscaliza\%C3\%A 7\%C3\%A3o\%20-\%20Sa\%C3\%BAde\%20(2).PDF

Woods, M., Paulus, T., Atkins, D. P., \& Macklin, R. (2016). Advancing qualitative research using qualitative data analysis software (QDAS)? Reviewing potential versus practice in published studies using ATLAS.ti and NVivo, 19942013. Social Science Computer Review, 34(5), 597617.

Yukl, G., Gordon, A., \& Taber, T. (2002). A hierarchical taxonomy of leadership behavior: integrating a half century of behavior research. Journal of Leadership Organizational Studies, 9(1), 15-32. 